\title{
The Epithelial Inward Rectifier Channel Kir7.1 Displays Unusual $\mathrm{K}^{+}$ Permeation Properties
}

\author{
Frank Döring, ${ }^{1}$ Christian Derst, ${ }^{3}$ Erhard Wischmeyer, ${ }^{1}$ Christine Karschin, ${ }^{1}$ Ralf Schneggenburger, ${ }^{2}$ \\ Jürgen Daut, ${ }^{3}$ and Andreas Karschin ${ }^{1}$ \\ ${ }^{1}$ Molecular Neurobiology of Signal Transduction and ${ }^{2}$ Department of Membrane Biophysics, Max-Planck-Institute for \\ Biophysical Chemistry, D-37070 Göttingen, Germany, and 3/nstitute for Normal and Pathological Physiology, University of \\ Marburg, D-35037 Marburg, Germany
}

Rat and human cDNAs were isolated that both encoded a 360 amino acid polypeptide with a tertiary structure typical of inwardly rectifying $\mathrm{K}^{+}$channel (Kir) subunits. The new proteins, termed Kir7.1, were $<37 \%$ identical to other Kir subunits and showed various unique residues at conserved sites, particularly near the pore region. High levels of Kir7.1 transcripts were detected in rat brain, lung, kidney, and testis. In situ hybridization of rat brain sections demonstrated that Kir7.1 mRNA was absent from neurons and glia but strongly expressed in the secretory epithelial cells of the choroid plexus (as confirmed by in situ patch-clamp measurements). In cRNA-injected Xenopus oocytes Kir7.1 generated macroscopic Kir currents that showed a very shallow dependence on external $\mathrm{K}^{+}\left(\left[\mathrm{K}^{+}\right]_{\mathrm{e}}\right)$, which is in marked contrast to all other Kir channels. At a

All eukaryotic potassium channels most likely are composed of either four (or two dimeric) subunits that differ significantly in architecture. In inwardly rectifying (Kir) $\mathrm{K}^{+}$channels each subunit consists of two hydrophobic membrane-spanning $\alpha$-helices (Ho et al., 1993; Kubo et al., 1993), in voltage-gated (Kv) channels they contain six transmembrane segments (Baumann et al., 1987; Kamb et al., 1987; Papazian et al., 1987), and in "duplicate pore" channels they have either four $(2+2$; Fink et al., 1996; Goldstein et al., 1996; Lesage et al., 1996) or eight segments (TOK, $6+2$; Ketchum et al., 1995; Zhou et al., 1995). Common to all $\mathrm{K}^{+}$ channels, however, is the presence of a conserved stretch of amino acids that lines the $\mathrm{K}^{+}$-selective ion conduction pathway (Hartmann et al., 1991; Yellen et al., 1991; Yool and Schwarz, 1991).

Kir channels are expressed in nearly all mammalian cells and are responsible for some of the common electrical characteristics. Unlike Kv channels, Kir channels do not activate on depolarization. They have a high open-state probability at negative membrane potentials and are blocked progressively as the cell membrane is depolarized. This facilitates switching between a polarized (resting) and depolarized (active) state. In the depolarized state the driving force for $\mathrm{K}^{+}$efflux is high, but never-

Received July 6, 1998; revised Aug. 13, 1998; accepted Aug. 13, 1998.

This work was funded in part by Deutsche Forschungsgemeinschaft Grants Ka1175/1-2 and Da177/7-2. We thank D. Reuter and S. Voigt for excellent technical help, Dr. M. Hollmann for the transcription vector pSGEM, and Professors W. Stühmer and E. Neher for generous support.

Correspondence should be addressed to Dr. A. Karschin, Max-Planck-Institute for Biophysical Chemistry, Molecular Neurobiology of Signal Transduction, Am Fassberg 11, 37070 Göttingen, Germany.

Copyright (C) 1998 Society for Neuroscience $\quad 0270-6474 / 98 / 188625-12 \$ 05.00 / 0$ holding potential of $-100 \mathrm{mV}$, the inward current through Kir7.1 averaged $-3.8 \pm 1.04 \mu \mathrm{A}$ with $2 \mathrm{mM}\left[\mathrm{K}^{+}\right]_{\mathrm{e}}$ and $-4.82 \pm 1.87$ $\mu \mathrm{A}$ with $96 \mathrm{~mm}\left[\mathrm{~K}^{+}\right]_{\mathrm{e}}$. Kir7.1 has a methionine at position 125 in the pore region where other Kir channels have an arginine. When this residue was replaced by the conserved arginine in mutant Kir7.1 channels, the pronounced dependence of $\mathrm{K}^{+}$ permeability on $\left[\mathrm{K}^{+}\right]_{\mathrm{e}}$, characteristic for other Kir channels, was restored and the $\mathrm{Ba}^{2+}$ sensitivity was increased by a factor of $\sim 25\left(K_{\mathrm{i}}=27 \mu \mathrm{M}\right)$. These findings support the important role of this site in the regulation of $\mathrm{K}^{+}$permeability in Kir channels by extracellular cations.

Key words: inwardly rectifying; choroid plexus; Kir7.1; pore loop; in situ hybridization; $\mathrm{Ba}^{2+}$ block theless outward current through Kir channels is decreased markedly. Depending on the degree of rectification, this "anomalous" rectification (Katz, 1949) allows for depolarization with little $\mathrm{K}^{+}$ efflux, which minimizes the energy required for ionic homeostasis of the cells. These rectification properties have been demonstrated to result from a voltage-dependent, high-affinity binding of intracellular $\mathrm{Mg}^{2+}$ and polyamines to distinct residues in the pore and C terminus (Ficker et al., 1994; Lopatin et al., 1994; Lu and MacKinnon, 1994; Wible et al., 1994; Fakler et al., 1995; Yang et al., 1995). The interaction of permeant and blocking ions with each other and with the channel is also unique for Kir channels and has been studied extensively (Hille, 1992; Nichols and Lopatin, 1997). The interaction of $\mathrm{K}^{+}$ions within a long channel pore possessing multiple binding sites is considered to be responsible for the nonlinear dependence of conductance on the extracellular $\mathrm{K}^{+}$concentration (Sakmann and Trube, 1984; Kubo et al., 1993).

Here we describe the molecular cloning of a member of a new Kir channel subfamily, Kir7.1, that shows $<37 \%$ identity with other Kir subunits. Our report contrasts a parallel, independent description in several important features of a highly similar human cDNA expressed in central neurons (Krapivinsky et al., 1998) and points out new, unusual channel properties. We show that the permeability of Kir7.1 is almost independent of external $\mathrm{K}^{+}$, which is in marked contrast to all other Kir family members. Dependence on external $\mathrm{K}^{+}$could be restored by replacement of one amino acid in the pore region. The selective expression in epithelial cells of the CNS is demonstrated by in situ hybridization and in situ measurements from choroid plexus epithelial cells. Together with the properties described here, the novel Kir7.1 
hKir 7.1 hKir 1.2 hKir 2.1 hKir 3.3 rKir5. 1 hKir 6.2

nKir $7 \cdot 1$ hKir 1.2 hKir2. 1 hK ir 3.3 rKir5. 1 $\mathrm{nK}$ ir 6.2

hKir 7.1 hKir 1.2 hKir2. 1 hK ir 3.3 rKir5. 1 hKir 6.2

nKir 7.1 hKir 1.2 hK $\mathrm{ir2} 2.1$ hKir 3.3 hKir5. 1 hKir 6.2

hKir 7.1 hKir 1.2 hK ir 2.1 nKir3. 3 rKir 5.1 hKir 6.2

hK i 7.1 hKir 1.2 hKir 2.1 nKir 3.3 rKir 5.1 hK ir 6.2

hKi 7.1 hKir 1.2 hKir2. 1 hK ir 3.3 rKir5. 1 hKir 6.2

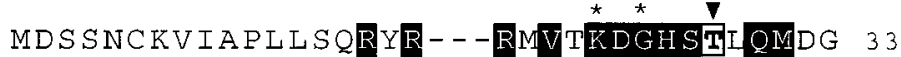
MTSVAKVYYSQTTQTESRPLMGPGIRRR- - RVLTKDGRSNVRMEH 43 MGSVRTNRYSIVSSEEDGMKLATMAVANGFGNGKSKVHTRQQCRSRFVKKDGHCNVQFIN 60 MAQENAAF SPGQEE - P PRRRGRQRYVEKDGRCNVQQGN 37 MSYYGSSYRIVNVDSKYPGYPPEHA-IAEKRRARRRLLHKDGSCNVYFKH 49 MLSRKGIIPEEYVLTRLAEDPAEPRYRARQR-RARFVSKKGNCNVAHKN 48
\end{abstract}

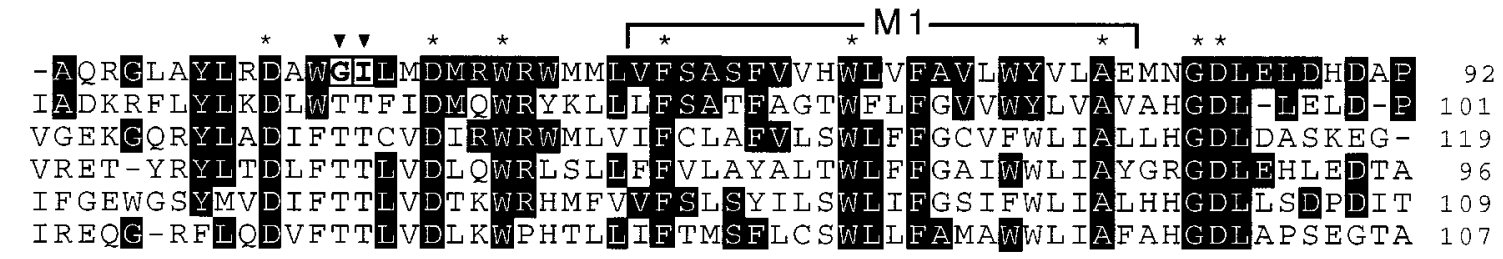
IREQG - RFLQDVFTTLVDL KWPHTLLIFTMSFLC SWLLEAMAWWL IAFAHGDLAP SEGTA 107

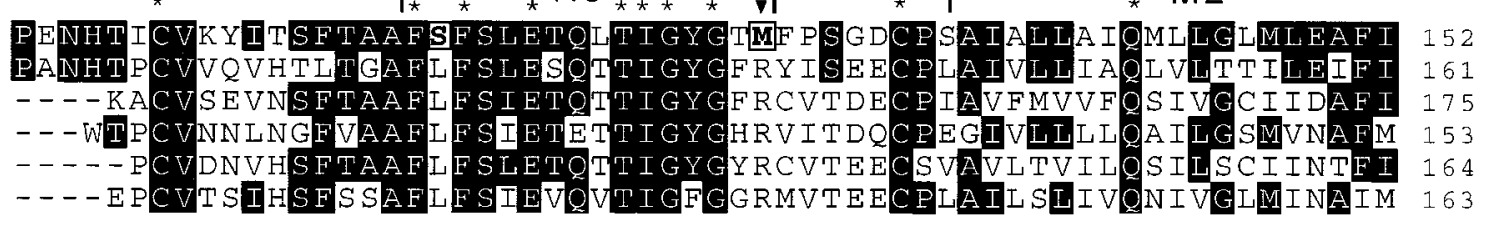

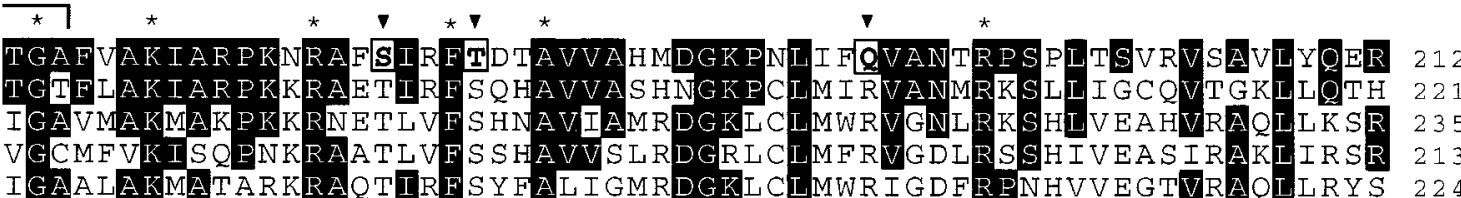
IGAALAKMATARKRAQTIRF SYFALIGMRDGRLCLMWR IGDFRPNHVVEGTVRAQLLRYS 224
LGCIFMKTAQAHRRAETLIF S KHAVIALR HGRLCFMLRVGDLRKSMI ISATIHMQVVRKT 223

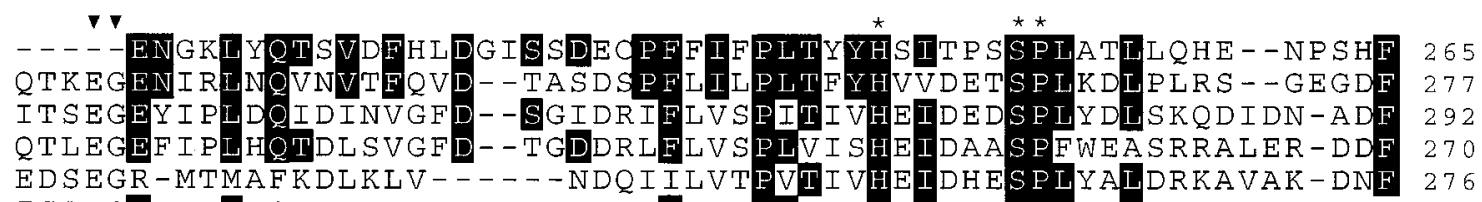
TSPEGEVVPIHQVDIPMENG - -VGGNS IELVAPLIIYHVIDANSPLYDLAPSDLHHHQDL 281
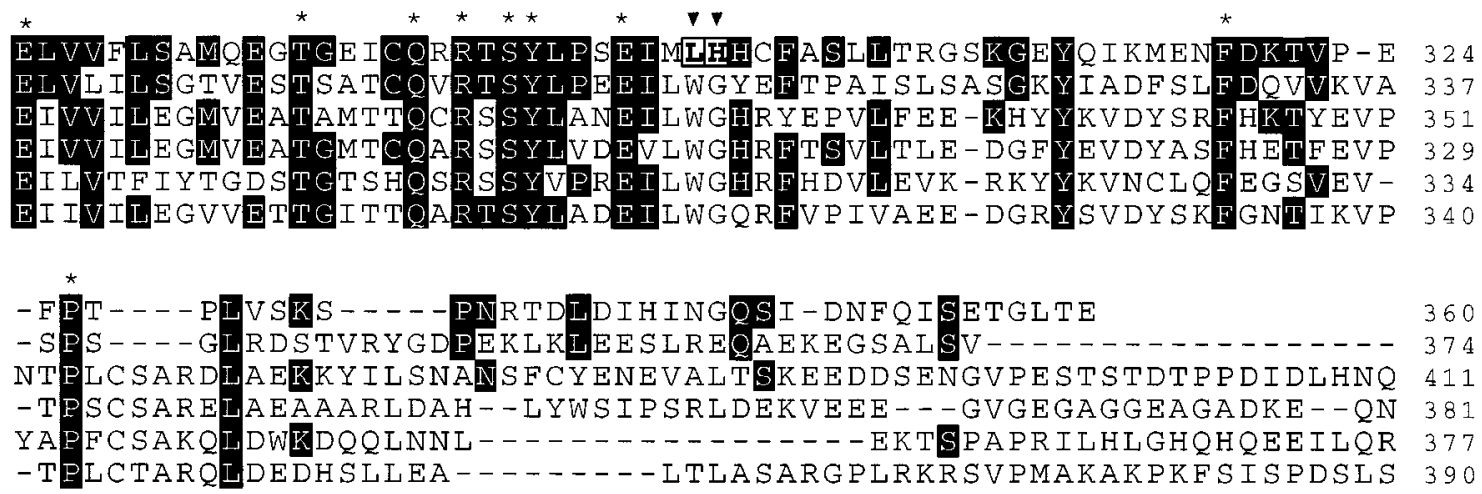

$\mathrm{hKir} 1.2$ hKir2.1 $\mathrm{hKir3} 3$ rKir5.1

$\begin{array}{ll}------1---R I S N V & 379 \\ \text { ASVPLEPRPLRRESEI } & 427 \\ \text { GCLP--- PPESESKV } & 393 \\ \text { SCHGEQL } & 384\end{array}$

Figure 1. Comparison of the amino acid sequences of Kir7.1 with representative subunits of other Kir subfamilies. The predicted 360 amino acids of human Kir7.1 (single-letter code) are shown aligned with sequences of human Kir1.2 (GenBank accession number U73192), human Kir2.1 (U12507) human Kir3.3 (U52152), rat Kir5.1 (X83581), and human Kir6.2 (D50582). Residues are shaded in black in instances in which other subunits are identical to Kir 7.1; asterisks denote residues conserved in all known Kir channels, and boxed residues (arrowheads) indicate where Kir7.1 is different from the consensus of all other Kir channels. Outlined also are the transmembrane segments M1 and M2 and the pore-forming P-region (H5). Amino acid gaps within the alignment are indicated by short bars. The GenBank accession number for the human and rat Kir7.1 sequences are AJ006128 and AJ006129, respectively. 
channels thus may contribute to the transepithelial transport of potassium.

\section{MATERIALS AND METHODS}

Molecular cloning. Several human expressed sequence tag (EST) sequences (GenBank accession numbers AA243775, AA406065, AA604625, and H97186) with Kir channel-like motifs were identified after an EST database with conserved Kir channel motifs was screened, using BLAST2.0 software (Altschul et al., 1997). Sequence analysis of two corresponding I.M.A.G.E. clones (clones IMAGp998D20569 and IMAGp998D201783, kindly supplied by RZPD, Max Planck Institute for Molecular Genetics, Berlin, Germany), using the prism Sequenase dye terminator kit on an automatic sequencer (Perkin-Elmer, Weiterstadt, Germany) revealed two fragmentary cDNAs that overlapped by $36 \mathrm{bp}$. With the appropriate primers $\left(5^{\prime}\right.$-CCGAATTC ${ }^{38} \mathrm{CCTGAGATGGA-}$ CAGCAGTAATTGC ${ }^{71}-3^{\prime} ; 5^{\prime}{ }^{294}{ }^{29}$ TCACCATTCATCTCAGC ${ }^{277}-3^{\prime} ; 5^{\prime}$ ${ }^{272}$ G TTCTGGCTGAGATGAATGGTGATTTGG ${ }^{299}-3^{\prime}$; and 5' $5^{538}{ }^{-G A}$ ATTGAAAAGCTCGA ${ }^{554}-3^{\prime}$ ) fragments were linked by "geneSOEing" (Horton et al., 1989) and subcloned into EcoRI-NotI sites of a pT7/T3 plasmid vector (Pharmacia, Uppsala, Sweden) to generate a complete open reading frame of $1080 \mathrm{bp}$ [nucleotides (nt) 44-1123] flanked by 43 bp of $3^{\prime}$-untranslated region (UTR) and 55 bp of $5^{\prime}$-UTR. Based on the novel human sequence (termed Kir7.1), the rat ortholog was amplified by RT-PCR from brain and testis poly $\left(\mathrm{A}^{+}\right) \mathrm{RNA}$ by means of the $5^{\prime}$-UTR primer 5'-AGAGAAATACAGCCTGAG-3' and the 3'-UTR antisense primer 5'-AAACTGGCTGGGTGTATTTAATAC-3'. To exclude PCR reading errors introduced by the Taq polymerase (Qiagen, Hilden, Germany), we subcloned and sequenced four independent PCR products on both strands. DNA analysis and sequence alignments were performed by using LASERGENE software (DNASTAR, Madison, WI) and Genetics Computer Group software (Madison, W I) run at the National Center for Biotechnology Information.

For functional expression in Xenopus oocytes the human Kir7.1 cDNA was subcloned further into the EcoRI-HindIII sites of the polyadenylating transcription vector pSGEM. The mutant Kir7.1 constructs Kir7.1M125R, Kir7.1M125R/P127V, and Kir7.1P127V were engineered by "geneSOEing" and checked by sequencing on both strands.

Northern blots. Northern blots were prepared from $2 \mu \mathrm{g}$ of $\operatorname{poly}\left(\mathrm{A}^{+}\right)$ RNA isolated from different tissues, fractionated by denaturing agarose gel electrophoresis and transferred to nylon membranes (Clontech, Palo Alto, CA). ${ }^{32} \mathrm{P}$-labeled cDNA probes were generated by random priming (Boehringer Mannheim, Mannheim, Germany) from a rat Kir7.1 fragment (nt 241-1046 in the open reading frame of the rat Kir7.1; GenBank accession number AJ006129). Blots were hybridized for $1 \mathrm{hr}$ at $42^{\circ} \mathrm{C}$ in ExpressHyb solution (Clontech) containing labeled cDNA with a specific activity of $10^{7} \mathrm{cpm} / \mathrm{ml}$. After high-stringency washes at $60^{\circ} \mathrm{C}$ in $0.1 \times$ $\mathrm{SSC} / 0.1 \%$ SDS the blots were exposed to x-ray Hyperfilm (Amersham, Buckinghamshire, UK) and developed after 1-3 d.

In situ hybridization. Wistar rats were decapitated under ether anesthesia, and their brains were removed and frozen on powdered dry ice. Tissue was stored at $-20^{\circ} \mathrm{C}$ until cutting. Sections $10-15 \mu \mathrm{m}$ were cut on a cryostat, thaw-mounted onto Silane-coated slides, and air-dried. After fixation for $30 \mathrm{~min}$ in $4 \%$ paraformaldehyde dissolved in PBS, the slides were washed in PBS, dehydrated, and stored in ethanol until hybridization.

Synthetic oligonucleotides were chosen from the Kir7.1 C terminus with least homology to other Kir sequences to minimize crosshybridization. Antisense oligonucleotides designed with least tendency of forming hairpins and self-dimers were as follows (base position on the coding strand is indicated): (1) $5^{\prime}-{ }^{897}$ GACTTGATACTCACCTTTGGAACCTCGAGTC ATTAGAGCTGC ${ }^{938}-3^{\prime}$ and (2) $5^{\prime \prime}$ - $^{972}$ GGTCAGTCCTATGTGGACTCTTAGAGACCACAGGAGTTGGATG ${ }^{1014}-3^{\prime}$. Oligonucleotides were $3^{\prime}$ end-labeled with ${ }^{35}$ S-dATP $(1200$ $\mathrm{Ci} / \mathrm{mmol}$; New England Nuclear, Boston, MA) by terminal deoxynucleotidyl transferase (Boehringer Mannheim) and used for hybridization at concentrations of $2-10 \mathrm{pg} / \mu \mathrm{l}\left(4 \times 10^{5} \mathrm{cpm} / 100 \mu \mathrm{l}\right.$ hybridization buffer per slide). For nonradioactive hybridizations digoxygeninlabeled sense and antisense cRNA probes were transcribed with T3 and $\mathrm{T} 7$ polymerase from a $805 \mathrm{bp}$ fragment of the rat Kir7.1 cDNA clone (nt 241-1046) according to the manufacturer's protocol (Boehringer Mannheim). Transcripts were used at a concentration of $\sim 800$ $\mathrm{pg} / \mu \mathrm{l}$ hybridization buffer. Criteria for specific labeling were identical hybridization patterns (1) for cRNA and oligonucleotide probes, (2) in separate experiments, and (3) on more than three different brain

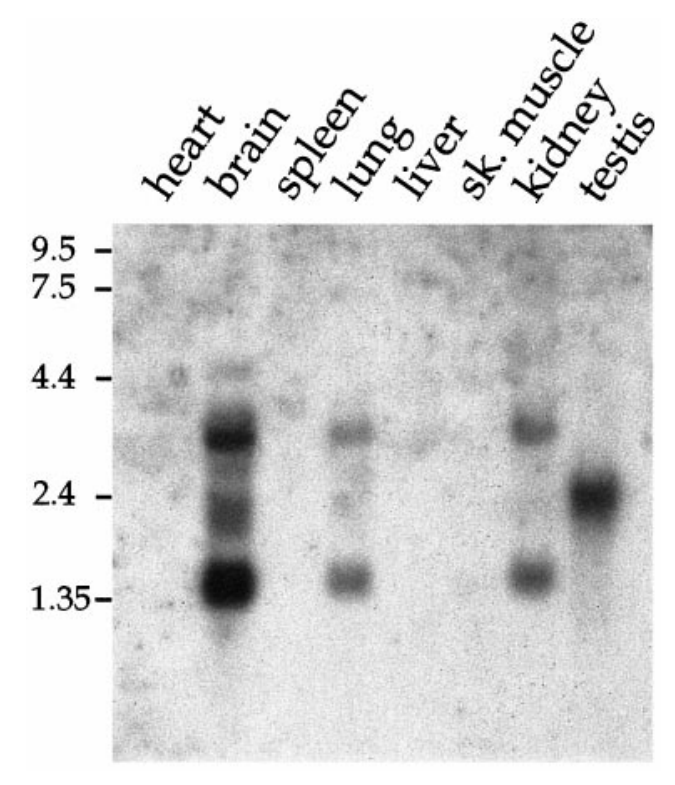

Figure 2. Northern blot analysis showing the distribution of Kir7.1 mRNA in rat heart, brain, spleen, lung, liver, skeletal muscle, kidney, and testis. Blots containing $2 \mu \mathrm{g}$ of poly $\left(\mathrm{A}^{+}\right)$RNA from each tissue were hybridized with ${ }^{32} \mathrm{P}$-labeled cDNA probes specific for rat Kir7.1. The positions of RNA size markers (in kb) are indicated (left).

sections. The brain sections were processed for radioactive and nonradioactive hybridization, and signals were detected as previously published (Karschin et al., 1996; Töpert et al., 1998). For identification and confirmation of brain structures with bright- and dark-field optics, the sections were Nissl-counterstained with cresyl violet (Paxinos and Watson, 1986; Paxinos et al., 1994). The following controls were performed: adjacent sections were (1) hybridized with sense oligonucleotide and cRNA probes, (2) digested with RNase A (50 ng/ml) for $30 \mathrm{~min}$ at $37^{\circ} \mathrm{C}$ before hybridization, and (3) prehybridized with a 20 to 50 -fold excess of unlabeled oligonucleotides before specific hybridization. These control hybridizations resulted in a complete loss of specific hybridization signal.

Electrophysiology. For expression in Xenopus laevis oocytes, capped run-off poly $\left(\mathrm{A}^{+}\right)$cRNA transcripts from linearized human Kir7.1 cDNA were synthesized, and $\sim 6 \mathrm{ng}$ was injected in defolliculated oocytes. Oocytes were prepared as described (Methfessel et al., 1986) and incubated at $19^{\circ} \mathrm{C}$ in ND96 solution [containing (in $\mathrm{mm}$ ) $96 \mathrm{NaCl}, 2 \mathrm{KCl}, 1$ $\mathrm{MgCl}_{2}, 1 \mathrm{CaCl}_{2}$, and $5 \mathrm{HEPES}$, pH 7.4], supplemented with $100 \mu \mathrm{g} / \mathrm{ml}$ gentamicin and $2.5 \mathrm{~mm}$ sodium pyruvate, and assayed $48 \mathrm{hr}$ after injection. Two-electrode voltage-clamp measurements were performed with a Turbo Tec-10 C amplifier (NPI Instruments, Tamm, Germany) and sampled via an EPC9 interface (Heka Electronics, Lambrecht, Germany), using PULSE/PULSEFIT software (Heka) on a Macintosh computer; data analysis was performed with IGOR software (WaveMetrics, Lake Oswego, OR). For the rapid exchange of external solutions, oocytes were placed in a small-volume perfusion chamber with a constant flow of solutions. In the experiments investigating $\mathrm{K}^{+}$permeability, extracellular $\mathrm{K}^{+}$and $\mathrm{Na}^{+}$were mutually exchanged to keep osmolarity constant [for example (in $\mathrm{mm}$ ) $96 \mathrm{KCl}, 2 \mathrm{NaCl}, 1 \mathrm{MgCl}_{2}, 1 \mathrm{CaCl}_{2}$, and 5 HEPES, pH 7.4].

Wistar rats at postnatal day P10 were decapitated under ether anesthesia, and the brains were isolated. From the lateral ventricles in coronal sections choroid plexi were dissected with micro forceps. The recording chamber was superfused with standard solution of the following composition (in mM): $140 \mathrm{NaCl}, 2.5 \mathrm{KCl}, 1 \mathrm{MgCl}_{2}, 2 \mathrm{CaCl}_{2}, 10 \mathrm{HEPES}$, and 10 glucose, adjusted to $\mathrm{pH}$ 7.4. Borosilicate glass patch pipettes had resistances of 4-7 M $\Omega$ when filled with the internal solution (in $\mathrm{mM}$ ): 130 K-gluconate, $20 \mathrm{KCl}, 10 \mathrm{HEPES}, 4 \mathrm{Na}_{2} \mathrm{ATP}, 5 \mathrm{Na}_{2}$ phosphocreatine, and 0.2 fura-2, adjusted to $\mathrm{pH}$ 7.2. Whole-cell recordings were performed on superficial epithelial cells under visual control by using an upright microscope equipped with infrared differential interference contrast (IR-DIC) optics. 

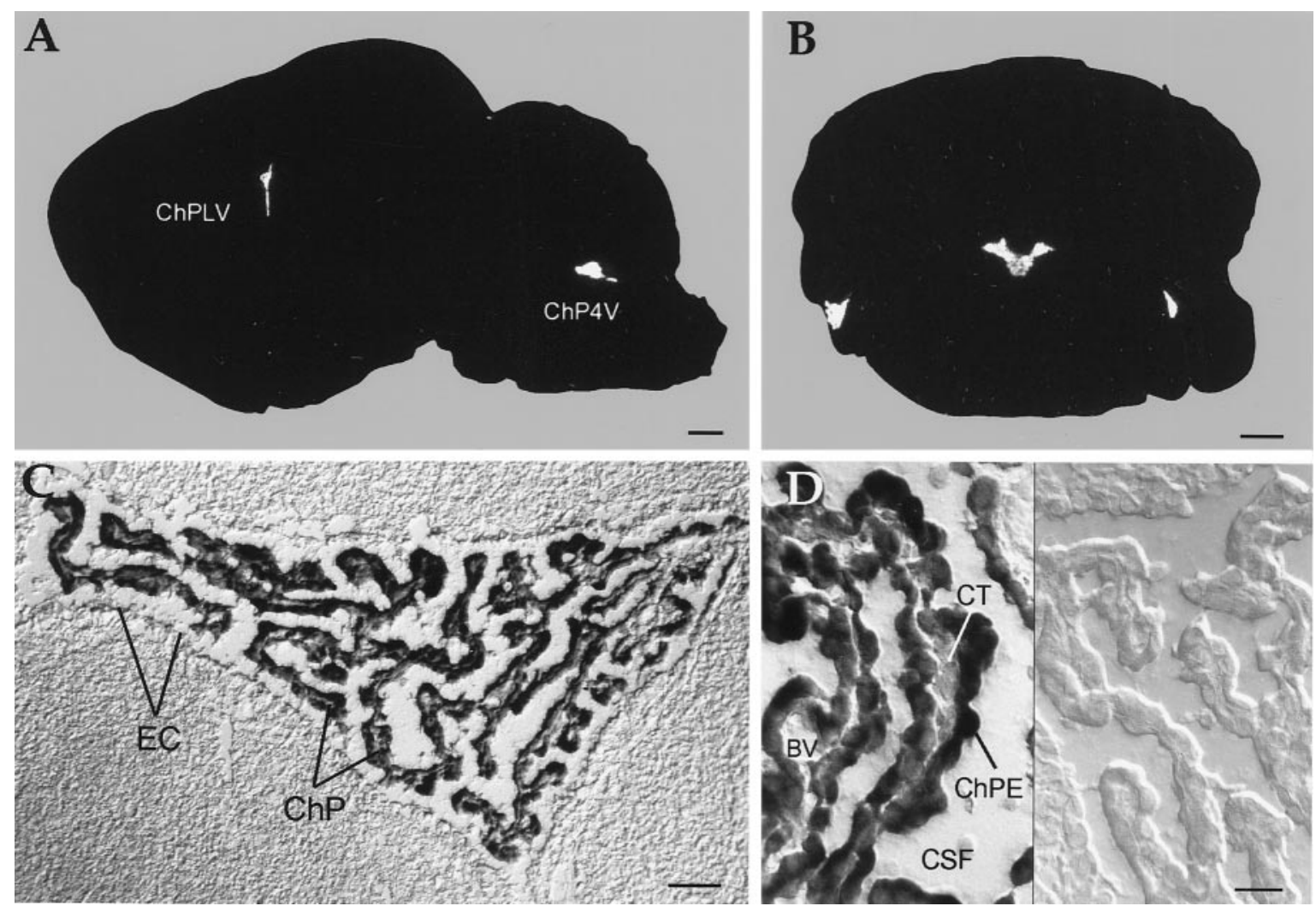

Figure 3. mRNA localization of Kir7.1 in the rat brain as revealed by in situ hybridization. Brain sections were hybridized with ${ }^{35} \mathrm{~S}$-labeled oligonucleotides $(A, B)$ or digoxigenin-labeled cRNA probes $(C, D)$, as described in Materials and Methods. X-ray film autoradiographs of sagittal $(A)$ and coronal $(B)$ sections show mRNA expression only in the choroid plexus of the fourth $(A, B)$ and lateral $(A)$ ventricles. Exposure time, 19 d. $C$, Bright-field photomicrographs with Nomarski optics show an overview of the choroid plexus $(C)$ and epithelial cells $(D)$ at higher magnification. Transcripts were found only by using antisense cRNA probes (left side), but not sense cRNA probes (right side). Note that epithelial cells surrounding the plexus vasculature are not labeled. $B V$, Blood vessel; $C h P 4 V$, choroid plexus of the fourth ventricle; ChPE, epithelial cells of the choroid plexus; $C h P L V$, choroid plexus of the lateral ventricle; $C S F$, cerebrospinal fluid; $C T$, connective tissue; $E C$, ependyma cells lining the ventricle; Scale bars: 1 mm in $A, B ; 50 \mu \mathrm{m}$ in $C ; 20 \mu \mathrm{m}$ in $D$.

\section{RESULTS}

\section{Primary structure of Kir7.1}

The human cDNA, including an entire open reading frame of $1080 \mathrm{bp}$ of a novel Kir channel subunit, was constructed from two overlapping EST clones and encoded a polypeptide of 360 amino acids with a calculated molecular weight $\left(M_{\mathrm{r}}\right)$ of 40.528 . Using untranslated region sequence information, we amplified with RTPCR the complete species ortholog of this sequence from rat brain and testis, confirming the integrity of the human cDNA. Within the 360 amino acids of the rat cDNA a total of 22 amino acid residues was found to be different from the human sequence. Protein sequence analysis of both coding regions showed the typical structural motifs of inwardly rectifying $\mathrm{K}^{+}$channels, i.e., two transmembrane segments M1 and M2 flanking a conserved pore-forming structure (P or H5 region), and short, cytoplasmic $\mathrm{N}$ - and C-terminal structures. After the completion of our study, another cDNA that was highly similar was isolated from the human fetal brain (Krapivinsky et al., 1998). By following their terminology and reflecting the cluster analysis that groups them independently in the phylogenetic tree (calculated by using the CLUSTAL algorithm of the LASERGENE software) (data not shown), we termed the rat and human sequences Kir7.1, representing members of a new Kir channel subfamily. When they were compared with other known Kir subunits, only moderate identity was found to members of the Kir2 $(<30 \%)$, Kir3 $(<28 \%)$, Kir5
$(<25 \%)$, and Kir6 (<25\%) subfamily (Fig. 1). Primary sequences were slightly more similar to Kir1.1 (ROMK1; 32\%), Kir1.2 (BIR10 or Kir4.1; 37\%) and Kir1.3 (34\%) subunits. Remarkably, Kir7.1 channels deviated from the Kir consensus scheme in a total of 11 amino acids (Fig. 1, arrowheads). Two consensus residues ( $\mathrm{E}$ and $\mathrm{G}$ after position 212 ) were completely missing; other exchanges occasionally were nonconserved with charge replacements (e.g., M125, Q190, H196).

As another noteworthy sequence feature, Kir7.1 contains four putative phosphorylation sites in the cytoplasmic regions. Three sites for protein kinase $\mathrm{C}$ are located at position 14 in the $\mathrm{N}$ terminus and at positions 169 and 201 in the $\mathrm{C}$ terminus, and a single potential protein kinase A phosphorylation site is situated further downstream at position 284. Second, an $N$-glycosylation site is present at position 95 in the extracellular M1-H5 linker. Occupancy by carbohydrates at the equivalent residue in Kir1.1 subunits (N117) has been shown to control tightly the open probability of the channels by stabilizing the open state (Schwalbe et al., 1995). A further remarkable difference between the Kir7.1 channel described here and its relatives of the Kir1 subfamily concerns the $\mathrm{pH}$ sensitivity. In Kir1.1 the channel activity is modulated by intracellular protons interacting with a unique lysine (K80) located in the $\mathrm{N}$ terminus close to the hydrophobic M1 segment (Fakler et al., 1996). Kir7.1 subunits, however, exhibit a methionine at the equivalent position. Finally, a nega- 
A
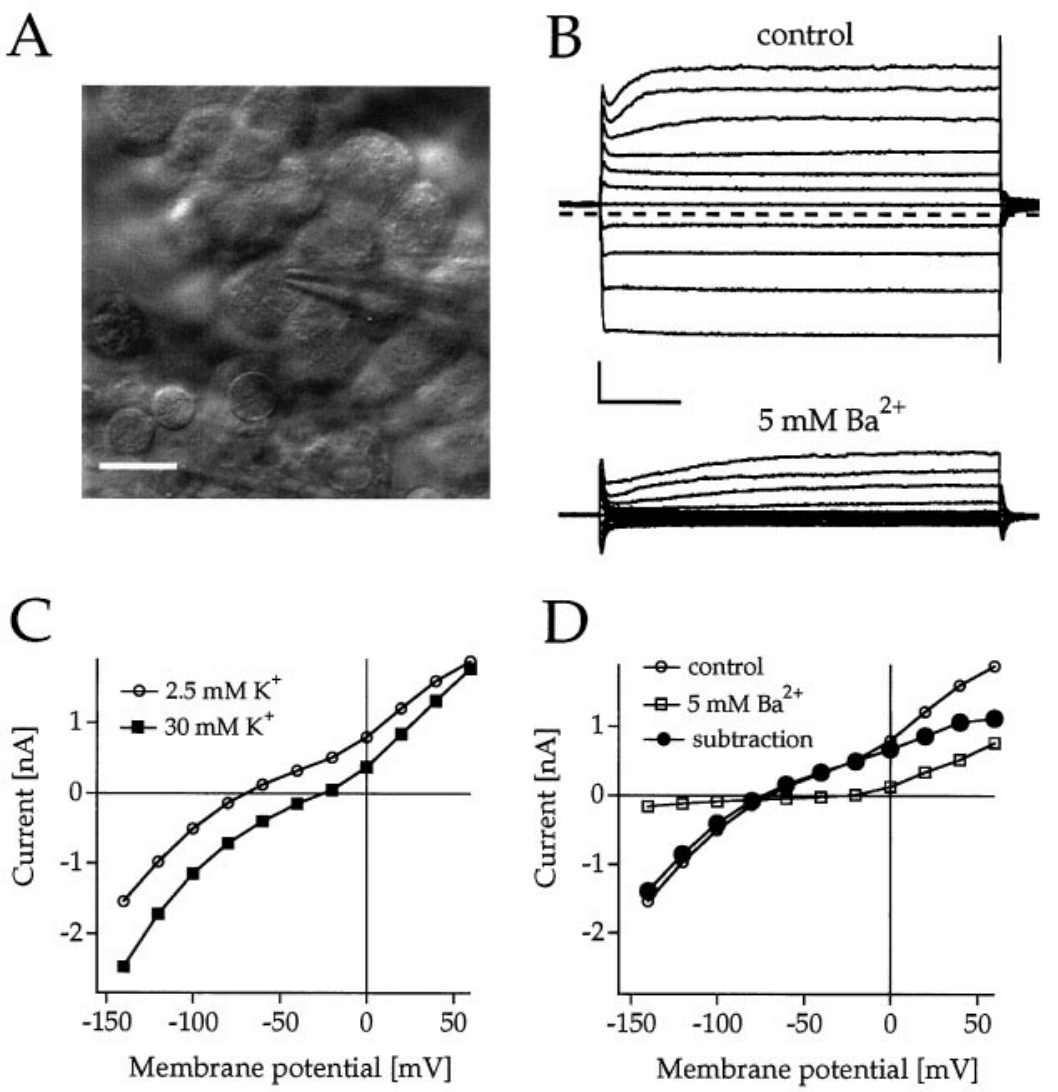

$\mathrm{D}$

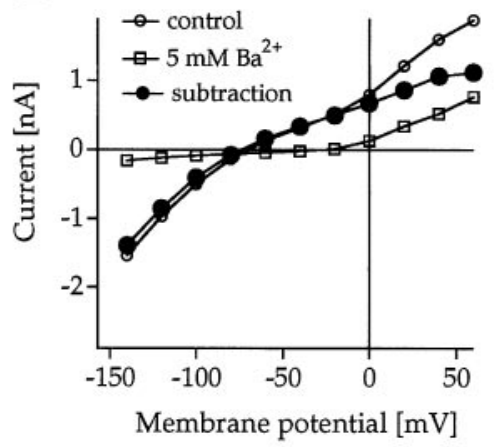

Figure 4. Demonstration of intrinsic inwardly rectifying $\mathrm{K}^{+}$ conductances inhibited by $\mathrm{Ba}^{2+}$ in rat choroid plexus epithelial cells in situ. $A$, IR-DIC image of an epithelial cell recorded with a patch-clamp pipette. Scale bar, $10 \mu \mathrm{m}$. $B$, Current responses of an epithelial cell to brief voltage steps between +60 and $-140 \mathrm{mV}$ from a holding potential of $V_{\mathrm{h}}=$ $-60 \mathrm{mV}$ in $2.5 \mathrm{~mm}\left[\mathrm{~K}^{+}\right]_{\mathrm{e}}$ in the absence (control) and presence of $5 \mathrm{~mm} \mathrm{Ba}^{2+}$. Calibration: $0.5 \mathrm{nA}, 20 \mathrm{msec}$. $C$, Current-voltage $(I-V)$ relationships of the endogenous current in $2.5(\bigcirc)$ and $30 \mathrm{~mm}\left[\mathrm{~K}^{+}\right]_{\mathrm{e}}(\mathbf{\square})$ measured at the end of the voltage pulse. $D, I-V$ relationship of the currents shown in $B$. The represents subtraction currents before and after the application of $5 \mathrm{~mm} \mathrm{Ba}^{2+}$. tively charged glutamate in M2 (E149) matches the E/D consensus residue for high-affinity binding of intracellular $\mathrm{Mg}^{2+} /$ polyamines and thus strong rectification (Ficker et al., 1994; Lopatin et al., 1994; Lu and MacKinnon, 1994; Wible et al., 1994; Fakler et al., 1995; Yang et al., 1995). However, a second negatively charged residue in the hydrophilic C-terminal domain of Kir2 channels, also involved in steep rectification (Taglialatela et al., 1994, 1995; Yang et al., 1995), is missing from Kir7.1 (S201). Also missing are C-terminal motifs for interactions with PDZ proteins of the cytoskeleton or the synaptic specialization, as have been observed among Kir channels, e.g., Kir2.1, Kir2.3, and Kir1.2 (Cohen et al., 1996; Wischmeyer and Karschin, 1996; Horio et al., 1997).

\section{Tissue and cellular distribution of Kir7.1}

Northern blots of mRNA extracted from rat tissues were hybridized with a labeled $805 \mathrm{bp}$ fragment of rat Kir7.1 to determine the overall tissue distribution (Fig. 2). Three bands of $\sim 1.4,2.4$, and $3.2 \mathrm{~kb}$ were detected and found to be distributed differentially. A strong $1.4 \mathrm{~kb}$ signal was present in the brain and weaker signals of this size were in the lung and kidney. The $3.2 \mathrm{~kb}$ transcripts had a similar distribution. Distinct hybridization that varied from the other pattern was seen for the $2.4 \mathrm{~kb}$ transcripts, which were very pronounced in the testis and possibly also were present in the brain. Kir7.1 mRNA could not be detected in heart, muscle, spleen, and liver.

In contradiction to the report of Krapivinsky et al. (1998), the cellular localization was found to be restricted to the brain ventricles (Fig. 3) when it was evaluated at higher resolution with in situ hybridization in rat brain sections. Using both short radiolabeled oligonucleotides from various regions and digoxigeninlabeled cRNA probes on sagittal and coronal rat brain sections, we were unable to detect significant signals in either central neurons or glia. Kir7.1 transcripts were found in the epithelial cells of the choroid plexus, which was strongly supported by immunoblots of brain tissue, using subunit-specific antibodies (data not shown). The choroid plexus of the mammalian brain forms the blood-cerebrospinal fluid barrier (Nilsson et al., 1992) and is located in the lateral, third, and fourth ventricles. Its cuboidal epithelium is sealed by tight junctions and overlies a highly vascularized tissue. In all sections the choroid plexus was strongly positive for Kir7.1 mRNA (Fig. 3C,D). No Kir7.1 mRNA signals were detected in the blood vessel endothelium or in ependyma cells lining the ventricle. A lower expression level was found in the neuroepithelium of the meninges surrounding the brain (data not shown). The other periventricular organs, possessing mostly capillaries with fenestrated endothelial cells, were either negative (pineal gland and median eminence) or were not analyzed (subcommissural organ, subfornical organ, and vascular organ of the lamina terminalis).

\section{Functional characterization}

To confirm the expression of Kir7.1 channels in CNS epithelial cells, whole-cell recordings were performed from epithelial cells of dissected rat choroid plexi that were recognized by their numerous vividly moving microvilli (Fig. $4 A$ ). When they were voltage-clamped at $-60 \mathrm{mV}$ and the membrane potential was stepped from $+60 \mathrm{mV}$ to $-140 \mathrm{mV}$, the cells displayed prominent outward and inward currents with a slope conductance of $12.7 \pm$ $3.9 \mathrm{nS}(n=4)$ in the range between -60 and $-120 \mathrm{mV}$. Elevation from 2.5 to $30 \mathrm{~mm}$ external $\mathrm{K}^{+}$positively shifted the $I-V$ relationship by $50-60 \mathrm{mV}$, indicative of a strong component of $\mathrm{K}^{+}$ conductance, but the elevation only slightly affected the chord conductance at negative potentials (Fig. 4C). On the basis of their 
A

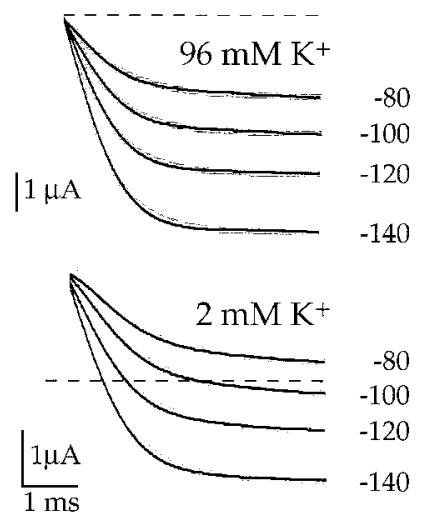

Figure 5. Characterization of macroscopic Kir7.1 inwardly rectifying currents in Xenopus oocytes. A, Current responses of an oocyte expressing Kir7.1 to brief steps between -80 and $-140 \mathrm{mV}$ from a holding potential of $V_{\mathrm{h}}$ $=0 \mathrm{mV}$ in 2 and $96 \mathrm{~mm}\left[\mathrm{~K}^{+}\right]_{\mathrm{e}}$, as indicated. $B$, Time constants of activation $\left(\tau_{\text {act }}\right)$ are plotted against the membrane potential for $\left[\mathrm{K}^{+}\right]_{\mathrm{e}}=2 \mathrm{~mm}(\mathbf{O})$ and for $\left[\mathrm{K}^{+}\right]_{\mathrm{e}}=96 \mathrm{~mm}(\bigcirc) . C$, Kir7.1 currents in response to fast voltage ramps show outward currents and a shift of reversal potentials with altering $\left[\mathrm{K}^{+}\right]_{\mathrm{e}}$, as indicated. $D$, Zero currents (reversal potentials, $E_{\mathrm{Rev}}$ ) of Kir7.1 currents that are in close agreement with $E_{\mathrm{K}}$ are plotted versus the extracellular concentration of $\mathrm{K}^{+}\left(\left[\mathrm{K}^{+}\right]_{\mathrm{e}}\right)$ on a semilogarithmic scale. Solid lines are linear regression fits to the data.
B
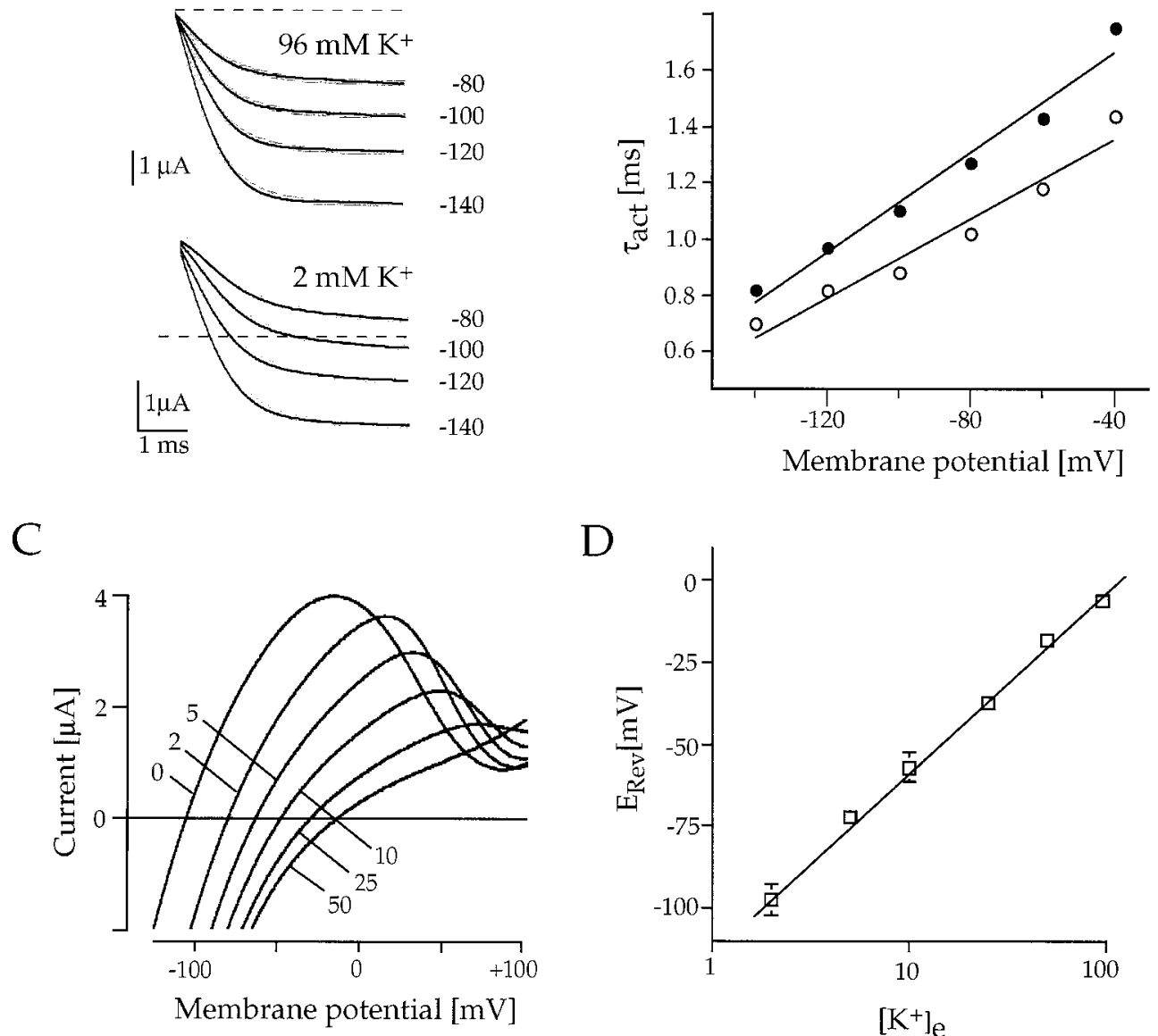

$\mathrm{D}$

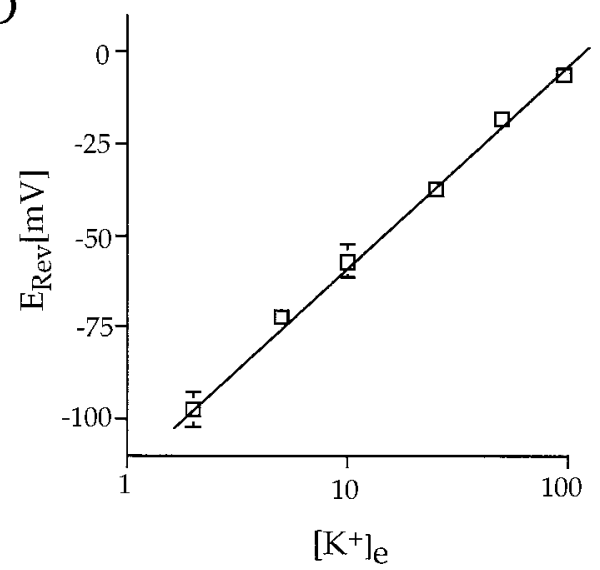

low $\mathrm{Ba}^{2+}$ sensitivity, $5 \mathrm{~mm} \mathrm{Ba}{ }^{2+}$ that completely inhibits recombinant Kir7.1 channels (see below) was superfused and found to suppress the inward current component completely (Fig. 4B,C). Point-by-point subtraction of current responses to a family of voltage steps before and after $\mathrm{Ba}^{2+}$ application revealed subtraction currents with reversal potentials, which indicated that $\mathrm{K}^{+}$permeable channels were primarily affected (Fig. 4C). Most interestingly, the $I-V$ curve of the $\mathrm{Ba}^{2+}$-sensitive current component was weakly rectifying in the inward direction and was very similar to that of Kir7.1 channels, with a nonlinear increase of conductance at negative potentials in varying external $\mathrm{K}^{+}$ concentrations (see below).

\section{Characterization of Kir7.1 in Xenopus oocytes}

When expressed in Xenopus laevis oocytes, the channels assembled from Kir7.1 subunits were also functionally unique among Kir channels and displayed previously unrecognized properties of $\mathrm{K}^{+}$permeation. At $2 \mathrm{~d}$ after the injection of Kir7.1 cRNA, large inward currents were recorded from oocytes. At a holding potential $\left(V_{\mathrm{h}}\right)$ of $-100 \mathrm{mV}$ the current amplitudes averaged $-3.8 \pm$ $1.04 \mu \mathrm{A}(n=8)$ with $2 \mathrm{~mm}$ external $\mathrm{K}^{+}\left(\left[\mathrm{K}^{+}\right]_{\mathrm{e}}\right)$ and $-4.82 \pm 1.87$ $\mu \mathrm{A}$ with $96 \mathrm{~mm}\left[\mathrm{~K}^{+}\right]_{\mathrm{e}}$. In uninjected or water-injected control oocytes only minute background currents $(<100 \mathrm{nA})$ were recorded. Channel activation kinetics in response to hyperpolarizing voltage pulses between -60 and $-140 \mathrm{mV}$ was rapid, and currents did not significantly inactivate during $0.5 \mathrm{sec}$ (also in $\mathrm{Na}^{+}$-free solution). The time constants of current activation determined from single exponential fits averaged $0.89 \pm 0.16$ msec $(n=6$; Fig. $5 A$ ) at a step potential of $-120 \mathrm{mV}$. As seen from the $\tau_{\text {act }} / V$ relationship in Figure $5 B$, however, the shift of time constants with $\left[\mathrm{K}^{+}\right]_{\mathrm{e}}$ was more moderate $(\sim 15-30 \mathrm{mV}$ between 2 and $\left.96 \mathrm{~mm}\left[\mathrm{~K}^{+}\right]_{\mathrm{e}}\right)$ than expected for Kir channels (Stanfield et al., 1994), suggesting that the activation characteristics are not solely dependent on $E_{\mathrm{m}}-E_{\mathrm{K}}$. When permeation and rectification properties were inspected with respect to $\left[\mathrm{K}^{+}\right]_{\mathrm{e}}$, ramp (Fig. 5C) and voltage-jump (Fig. 6) currents demonstrated that Kir7.1 channels were highly selective for $\mathrm{K}^{+}$ions. The measured zero current potentials for six cells were $-97.7 \mathrm{mV}(2$ $\left.\mathrm{mm} \mathrm{K}^{+}\right),-72.3 \mathrm{mV}\left(5 \mathrm{~mm} \mathrm{~K}^{+}\right),-57.3 \mathrm{mV}\left(10 \mathrm{~mm} \mathrm{~K}{ }^{+}\right),-37.5$ $\mathrm{mV}\left(25 \mathrm{~mm} \mathrm{~K}^{+}\right),-18.2 \mathrm{mV}\left(50 \mathrm{mM} \mathrm{K}^{+}\right)$, and $-6.4 \mathrm{mV}(96 \mathrm{~mm}$ $\mathrm{K}^{+}$), coinciding well with $E_{\mathrm{K}}$ as predicted from the Nernst equation. As expected, the zero current potentials followed $\left[\mathrm{K}^{+}\right]_{\mathrm{e}}$ with a slope of $\sim 54 \mathrm{mV}$ per decade, which is close to the $58 \mathrm{mV}$ per decade expected for a perfectly $\mathrm{K}^{+}$-selective channel, indicating that the conductance was carried predominantly by $\mathrm{K}^{+}$ions (see Fig. 5D). Also, the "activation potential" in these experiments at which rectification occurs changed in accordance with $E_{\mathrm{K}}$. It is noteworthy that channels carried a substantial outward flux, especially at low $\left[\mathrm{K}^{+}\right]_{\mathrm{e}}$. With $2 \mathrm{~mm}$ external $\mathrm{K}^{+}$the currents reached their peak $\sim 100 \mathrm{mV}$ positive to $E_{\mathrm{K}}$ (zero current), which is far beyond what has been observed for Kir2.1 channels ( $\sim 40$ $\mathrm{mV}$ ) and likely points to a low sensitivity to block by internal $\mathrm{Mg}^{2+} /$ polyamines (see Discussion).

The shape of the $I-V$ relationship of Kir7.1 was completely unlike that of other Kir channels (Fig. 6). The $I-V$ curve, even at 
A

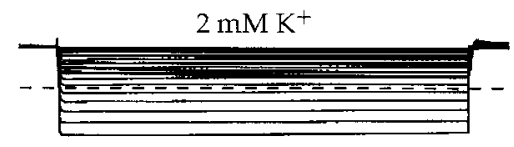

$25 \mathrm{mM} \mathrm{K}^{+}$

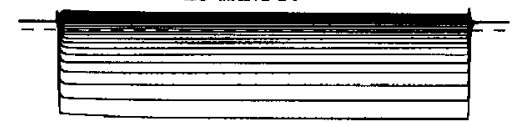

$96 \mathrm{mM} \mathrm{K}^{+}$

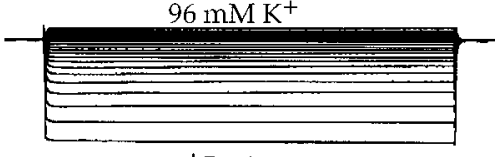

$5 \mu \mathrm{A}$

$100 \mathrm{~ms}$

C

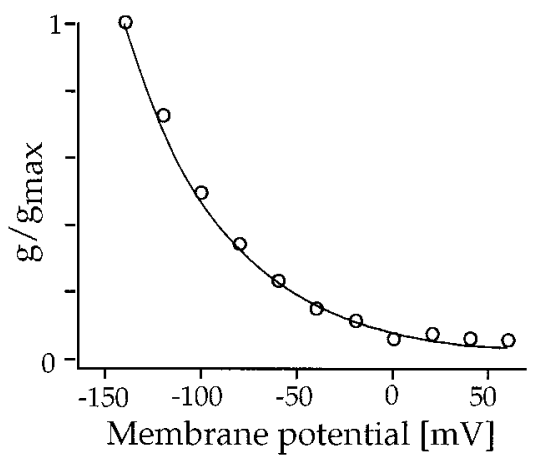

B

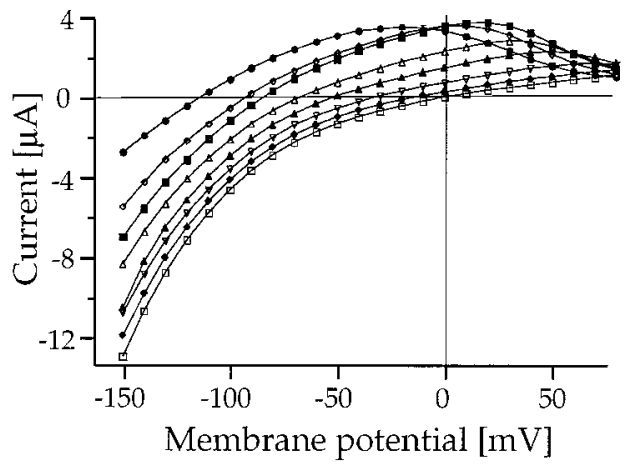

D

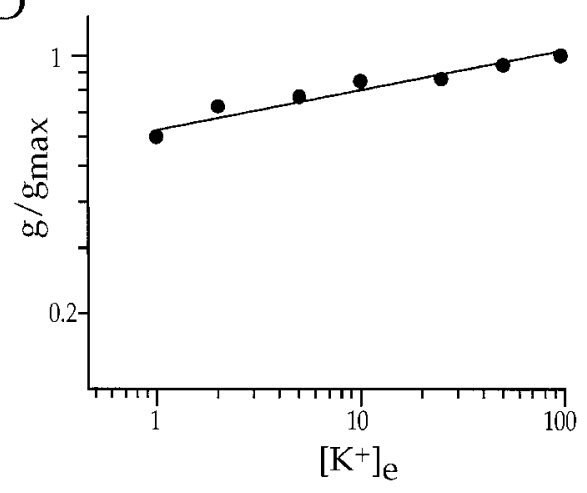

Figure 6. Whole-cell voltage-clamp responses of Xenopus oocytes expressing Kir7.1 channels. $A$, Macroscopic currents in response to $500 \mathrm{msec}$ voltage steps between -80 and $-140 \mathrm{mV}$ from a holding potential of $V_{\mathrm{h}}=0 \mathrm{mV}$ in 2, 25, and $96 \mathrm{~mm}\left[\mathrm{~K}^{+}\right]_{\mathrm{e}}$, as indicated. $B$, Current-voltage $(I-V)$ relationship of Kir7.1 currents measured at the end of the $500 \mathrm{msec}$ voltage pulse in $0(\mathbf{)}), 1$ $(\diamond), 2(\boldsymbol{\square}), 5(\triangle), 10(\mathbf{\Delta}), 50(\diamond)$, and $96 \mathrm{~mm}$ $(\square)$ extracellular $\mathrm{K}^{+}$. $C$, Normalized chord conductances of Kir7.1 $\left(G / G_{\max }\right)$ in $96 \mathrm{~mm}$ $\mathrm{K}^{+}$are plotted versus the membrane voltage. The $G-V$ relationship was fit by a single exponential. $D$, Double-logarithmic plot of the Kir7.1 chord conductance as a function of $\left[\mathrm{K}^{+}\right]_{\mathrm{e}}$. Conductances were measured at $G_{\max }$, and the data were fit to $G=$ $m\left(\left[\mathrm{~K}^{+}\right]_{\mathrm{e}}\right)^{\mathrm{n}}$, where $m$ and $n$ are variables. negative potentials beyond $-120 \mathrm{mV}$, was not linear but showed a curvature of nonsaturating conductance at all $\mathrm{K}^{+}$concentrations (Fig. 6B). This behavior was indicated clearly in the voltage dependence of the measured chord conductances ( $G-V$ curve), which did not follow the typical Boltzmann function but were well described by a monoexponential fit (Fig. 6C). Most strikingly, however, the slope conductances of Kir7.1 currents did not follow the rule of a "roughly square-root dependence" on $\left[\mathrm{K}^{+}\right]_{\mathrm{e}}$ as has been observed before for native and other recombinant Kir channels (Sakmann and Trube, 1984; Wischmeyer et al., 1995). As shown in the double-logarithmic plot in Figure $6 D$, the conductance increased only slightly with varying $\left[\mathrm{K}^{+}\right]_{\mathrm{e}}$. Using the equation given in the legend of Figure 5, we calculated an exponent of 0.1 , which represents a uniquely low value. This indicates that the permeation of $\mathrm{K}^{+}$ions through the Kir7.1 pore does not obey the criteria established before for a conventional multi-ion single-file pore (Hille and Schwarz, 1978).

The sensitivity of Kir7.1 to the open channel blockers $\mathrm{Ba}^{2+}$ and $\mathrm{Cs}^{+}$was analyzed by using voltage ramps between -150 and $+60 \mathrm{mV}$. The $K_{\mathrm{i}}$ value for $\mathrm{Ba}^{2+}$ block was $670 \mu \mathrm{M}$ at $-100 \mathrm{mV}$ (Fig. 7A,B), which is one to two orders of magnitude higher than for other members of the Kir family. Kir7.1 channels were even $\sim 40$ times less sensitive to $\mathrm{Cs}^{+}$with a $K_{\mathrm{i}}$ value of $26.9 \mathrm{~mm}$ (data not shown). Thus, Kir7.1 channels had a very low affinity to both blockers as compared with other Kir channels described previously (Töpert et al., 1998). The block of Kir channels by external cations has been found to show a characteristic time and voltage dependence. The blocking effect was much faster and larger at more negative potentials, suggesting an open channel block at a deep site in the pore after the opening of the channels. In Kir7.1 the time course of the onset of $\mathrm{Ba}^{2+}$ block and its voltage dependence (Fig. 7C,D) was similar to that found in other members of the Kir channel family.

\section{Characterization of mutant Kir7.1M125R channels}

In the primary sequence of Kir7.1 two residues adjacent to the conserved $\mathrm{K}^{+}$channel pore signature $\mathrm{G}-\mathrm{Y}-\mathrm{G}$ are more similar to $\mathrm{Kv}$ channels than to other Kir channels. One is the replacement of an arginine at position +2 after the G-Y-G motif, highly conserved among Kir channels, by a methionine residue typical for $\mathrm{Kv}$ channels. The other is a consensus proline present at position +4 in all $\mathrm{Kv}$ channels but that is absent from Kir channels (Fig. $8 A$ ). The phenylalanine at position 126 between these two residues is equivalent to the regulatory site for $\mathrm{K}^{+}$ions in voltage-dependent RCK4 channels (Pardo et al., 1992), as well as a Kv channel external binding site for TEA (MacKinnon and Yellen, 1990; Heginbotham and MacKinnon, 1992; Ludewig et al., 1993) and C-type inactivation in other Kv channels (LopezBarneo et al., 1993). We did not pursue testing potential functional roles of this aromatic amino acid $(+3)$, because Kir7.1 channels were found to be insensitive to the application of $10 \mathrm{~mm}$ $\mathrm{TEA}^{+}$(data not shown). Also, we were unable to investigate the role of the proline, because exchange by a valine did not yield expression of functional Kir7.1 channels. The residue at position +2 had been suggested before to play an important role in channel interaction with extracellular $\mathrm{K}^{+}$ions (Kubo, 1996; Yang et al., 1997). Therefore, we investigated the effects of reintroducing the conserved arginine at position 125 in Kir7.1. Mutant Kir7.1M125R, like wild-type channels, rapidly activated on hyperpolarizing voltage steps. The inward currents showed a moderate initial inactivation component at potentials negative to $-100 \mathrm{mV}$ (Fig. 8B). With high $96 \mathrm{~mm}$ external $\mathrm{K}^{+}$, inward 

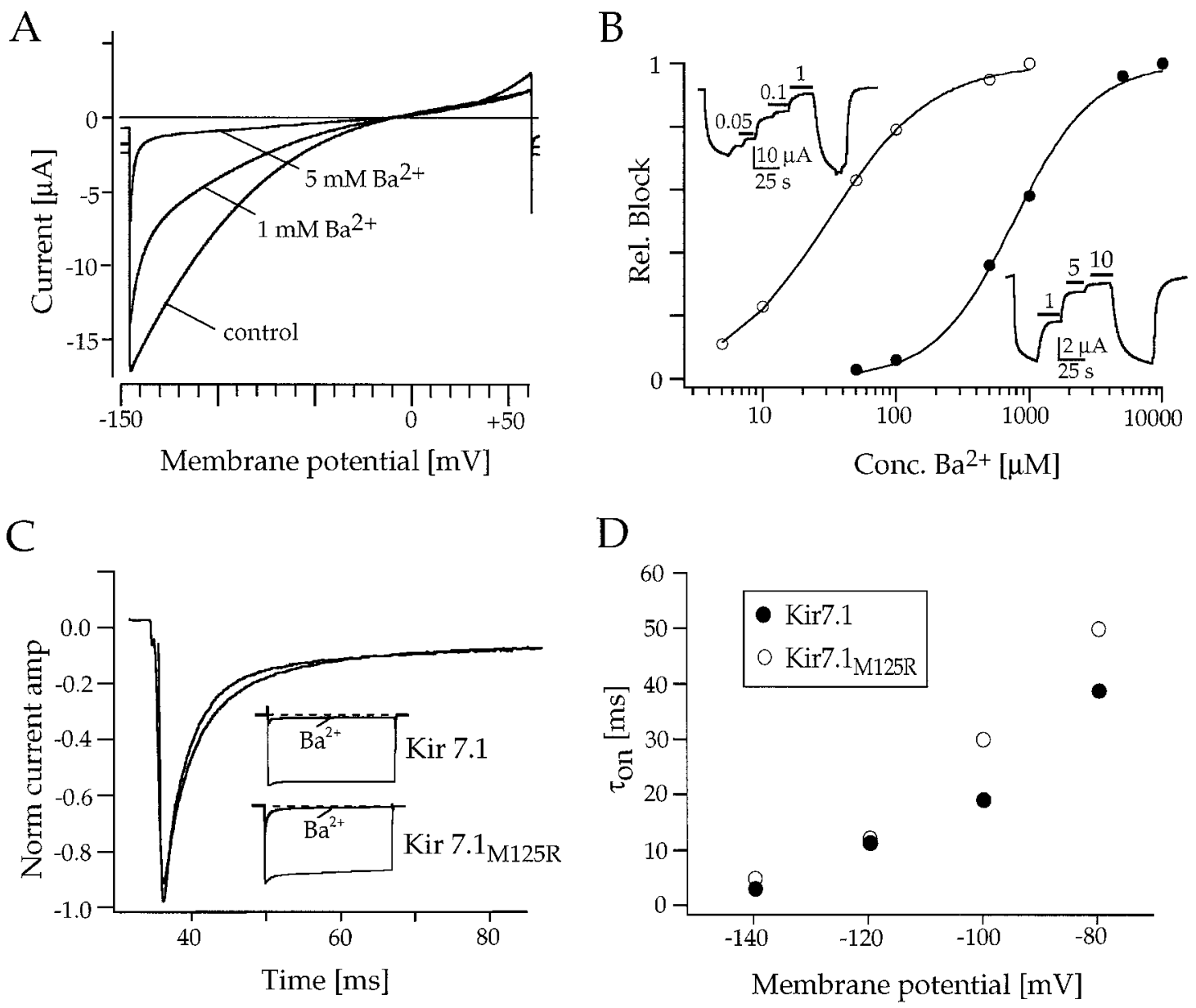

Figure 7. Analysis of the block by extracellular $\mathrm{Ba}^{2+}$ of wild-type Kir7.1 and mutant Kir7.1M125R in Xenopus oocytes. $A$, Ramp current responses to voltage ramps of $2 \mathrm{sec}$ duration between -150 and $+60 \mathrm{mV}$ show the voltage dependence of $I_{\mathrm{Kir} 7.1}$ block by 1 and $5 \mathrm{~mm} \mathrm{Ba}{ }^{2+}$. B, Current inhibition relative to a maximum block by a saturating concentration of $\mathrm{Ba}^{2+}$ is plotted versus the concentration of the blocking cation at a holding potential of $V_{\mathrm{h}}=-80 \mathrm{mV}$. Curves are least-squares fits of data points to a Hill equation $\left(1 / 1+\left[A / K_{\mathrm{i}}\right]^{n}\right.$, giving a $K_{\mathrm{i}}$ for Ba ${ }^{2+}$ of $670 \mu \mathrm{M}$ for Kir7.1 $(\bullet)$ and a $K_{\mathrm{i}}$ for $\mathrm{Ba}^{2+}$ of $27 \mu \mathrm{M}$ for Kir7.1M125R $(\bigcirc) . K_{\mathrm{i}}$ is the concentration of cation producing $50 \%$ block; $A$ and $n$ are variables. Insets, Shown are continuous recordings of wild-type and mutant Kir7.1 currents at $-80 \mathrm{mV}$ under $\mathrm{Ba}^{2+}$ block. The application of the blocker is indicated by black bars. $C$, Timeand voltage-dependent block of wild-type and mutant Kir7.1M125R channels by $\mathrm{Ba}^{2+}$. Shown are single-exponential fits to the time course of the current block by a saturating concentration of $\mathrm{Ba}^{2+}$ (10 mM for Kir7.1 and $500 \mu \mathrm{M}$ for Kir7.1M125R). Insets, Shown are the complete current responses of Kir7.1 and Kir7.1M125R channels to $500 \mathrm{msec}$ voltage steps between 0 and $-120 \mathrm{mV}$. D, Relationship of time constants of activation $\left(\tau_{\text {on }}\right)$ and the membrane potential for wild-type Kir7.1 (@) and mutant Kir7.1M125R (O) channels at 96 mM external $\mathrm{K}^{+}$.

currents recorded from oocytes injected with Kir7.1M125R cRNA had amplitudes similar $(-5.43 \pm 0.82 \mu \mathrm{A}$ at a holding potential of $-100 \mathrm{mV} ; n=8$ ) to wild-type channels. However, with low $2 \mathrm{~mm}$ external $\mathrm{K}^{+}$, mutant channels displayed only minute inward currents $(0.29 \pm 0.21 \mu \mathrm{A}$ at $-100 \mathrm{mV}, n=8)$. Analysis of the permeation properties demonstrated that mutated Kir7.1M125R channels were also selective for $\mathrm{K}^{+}$ions (Fig. $9 B, C)$. Zero current potentials followed $\left[\mathrm{K}^{+}\right]_{\mathrm{e}}$ with $\sim 52 \mathrm{mV}$ per decade.

In agreement with wild-type Kir7.1, the currents through Kir7.1M125R channels showed a shallow voltage dependence of conductance on hyperpolarization, and the $I-V$ relationship still exhibited mild downward curvature at most negative potentials (see Fig. 8C). In contrast to wild-type Kir7.1, but typical of other members of the Kir family, mutant Kir7.1M125R channels conducted little outward current (see Fig. $8 C$ ) and conductance levels saturated at potentials negative to $-100 \mathrm{mV}$, as illustrated in the $G-V$ curve of Figure $9 C$. Most intriguingly, the mutation was found to restore the dependence of conductance on $\left[\mathrm{K}^{+}\right]_{\mathrm{e}}$. The double-logarithmic plot in Figure $9 D$ revealed that the conductance of mutant Kir7.1M125R channels was proportional to $\left[\mathrm{K}^{+}\right]_{\mathrm{e}}{ }^{0.8}$. Thus the dependence of maximal conductance on external $\left[\mathrm{K}^{+}\right]$was more pronounced in Kir7.1M125R than in any other Kir channel, despite the fact that in the wild-type channels the conductance was almost independent of external $\left[\mathrm{K}^{+}\right]$.

In Kir2.1 the consensus arginine had been suggested to function as barrier for cationic blockers, also supporting its crucial role in channel function (Sabirov et al., 1997). When probed with $\mathrm{Ba}^{2+}$ the blocking rate (time courses of block by saturating $\mathrm{Ba}^{2+}$ concentrations fit by single exponentials) in mutant Kir7.1M125R channels was not much different from wild-type channels. Our data indicate that, despite the presence of the positive charge, the approach of $\mathrm{Ba}^{2+}$ ions to their binding site(s) remained virtually unaltered (see Fig. 7C,D). However, the $\mathrm{Ba}^{2+}$ block differed in sensitivity between wild-type and mutant channels, as can be seen from the concentration-response relationship determined in ramp-evoked and steady-state currents (see Fig. 7B). Introducing a positive charge in mutant Kir7.1M125R channels dramatically 
A
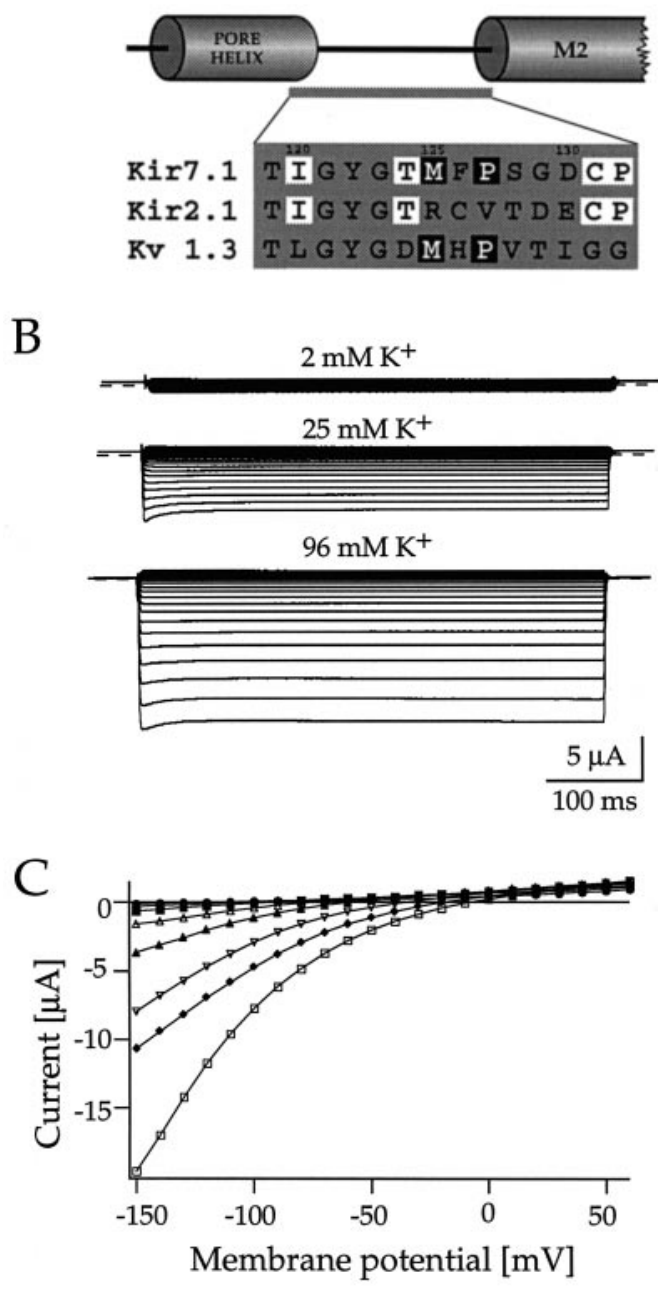

Figure 8. Macroscopic currents through mutant Kir7.1M125R channels in Xenopus oocytes. A, Sequence alignment of the core region between the pore helix and the M2 (inner) helix of Kir7.1, Kir2.1, and Kv1.3 channels, as suggested by Doyle et al. (1998), show the residues mutated in this study. Boxed in white are residues conserved in all Kir channels; boxed in black are residues identical between Kir7.1 and mostly present in $\mathrm{Kv}$ channels. $B$, Whole-cell voltage-clamp responses of oocytes expressing mutant Kir7.1M125R channels to $500 \mathrm{msec}$ voltage steps between -80 and $-140 \mathrm{mV}$ from a holding potential of $V_{\mathrm{h}}=0 \mathrm{mV}$ in 2, 25, and $96 \mathrm{~mm}$ $\left[\mathrm{K}^{+}\right]_{\mathrm{e}}$, as indicated. $C$, Current-voltage $(I-V)$ relationship of Kir7.1M125R currents measured at the end of the $500 \mathrm{msec}$ voltage pulse in $0(\bullet), 1(\diamond)$, $2(\square), 5(\triangle), 10(\Delta), 50(\diamond)$, and $96 \mathrm{~mm}(\square)$ extracellular $\mathrm{K}^{+}$.

affected the steady-state block, causing an $\sim 25$-fold increase in the affinity for $\mathrm{Ba}^{2+}\left(K_{\mathrm{i}}=27 \mu \mathrm{M}\right)$. These findings may have important implications for the elucidation of the mechanisms underlying the block of Kir channels by external cations (see Discussion).

\section{DISCUSSION}

Our report describes both rat and human sequences of a new type of inward rectifier $\mathrm{K}^{+}$channel, Kir7.1, that group in a separate phylogenetic cluster. The unique structures were found to be reflected in several previously unrecognized channel properties. A highly similar human channel with an extremely low singlechannel conductance $(\sim 50 \mathrm{fS})$ has been reported in a parallel study (Krapivinsky et al., 1998). Using polyclonal peroxidase- detected antibodies generated from GST-Kir7.1 fusion proteins, they found Kir expression to be widely expressed in the brain, most predominantly in cerebellar Purkinje cells and pyramidal cells in the hippocampus. In contrast, we detected no Kir7.1 transcripts in any neuronal, glial, or connective tissue cell population by in situ hybridization, although a distinct signal was found in the choroid plexus and in the meninges. The reason for this discrepancy is unknown, because on Western blots we also detect Kir7.1 immunoreactivity only in the choroid plexus and meninges, but not in any other brain region. Our experiments with plexi dissected from the brain in fact demonstrate the presence of a weakly rectifying $\mathrm{K}^{+}$current that resembles the Kir7.1 current in oocytes and confirms an earlier report (Kotera and Brown, 1994) that this current contributes a major component to the intrinsic $\mathrm{K}^{+}$conductance of the epithelial cells. These cells are rich in $\mathrm{Na}^{+} / \mathrm{K}^{+}$-ATPase (Nilsson et al., 1992) and are involved in the regulation of the composition of the CSF. The $\mathrm{K}^{+}$concentration in the CSF $\left(\sim 2 \mathrm{mM} \mathrm{K}^{+}\right)$is controlled tightly and is lower than in the blood or in the cerebral interstitium $\left(\sim 4 \mathrm{mM} \mathrm{K}^{+}\right)$, indicating outward transport of $\mathrm{K}^{+}$ions from the CSF. It is conceivable that open Kir7.1 channels at the abluminal side of the epithelial cells appropriately serve the function of $\mathrm{K}^{+}$clearance from the CSF. The weak rectification of Kir7.1 would allow for a larger $\mathrm{K}^{+}$ efflux (at low $\left[\mathrm{K}^{+}\right]_{\mathrm{e}}$ ) than the more strongly rectifying Kir channels found in other regions of the brain. Our Northern blot analysis suggests that Kir7.1 transcripts of different length likely are also present in the epithelia of lung, kidney, and testis. In these tissues Kir channels are located mostly at the basolateral cell membrane and balance the $\mathrm{K}^{+}$fluxes generated by channels, transporters, and pumps on the apical side (Wang et al., 1997). We thus conclude that Kir7.1 channels are likely to be involved in the regulation of transepithelial $\mathrm{K}^{+}$transport.

It has long been known that inward rectification in many cell types depends not only on membrane potential $\left(E_{\mathrm{m}}\right)$ but also on the potassium equilibrium potential $\left(E_{\mathrm{K}}\right)$. In various cell types inward rectification could be described as a function of $\left(E_{\mathrm{m}}-\right.$ $E_{\mathrm{K}}$ ) (Noble, 1965; Hagiwara and Takahashi, 1974; Hille and Schwarz, 1978). Subsequently, it has been suggested that the inward rectifier senses a combination of $\left[\mathrm{K}^{+}\right]_{\mathrm{e}}$ (but not $\left.\left[\mathrm{K}^{+}\right]_{\mathrm{i}}\right)$ and $E_{\mathrm{m}}$ (Matsuda, 1991). It was postulated that the positively charged arginine at position 148 in Kir2.1, which may form exposed salt bridges with an opposite glutamate residue in the tetrameric channel, is involved in the regulation of Kir channel conductance and selectivity by external $\mathrm{K}^{+}$(Kubo, 1996; Yang et al., 1997). An analogous arginine near the GYG pore motif is conserved in all other Kir channels (except in Kir7.1, where it is replaced by the methionine at position 125). Substitution by a tyrosine in Kir2.1 (the only functional mutation at this site) shifted the dependence of $\tau_{\text {act }} /$ conductance (at any external $\mathrm{K}^{+}$), resulting in apparently smaller amplitudes and a nonsaturating conductance. Surprisingly, our measurements show that the inverse exchange in Kir7.1 channels (M125R) reduces current amplitudes only at low $\left[\mathrm{K}^{+}\right]_{\mathrm{e}}$ and increases the steepness of the $G-V$ curve quite moderately (leading to saturation at very negative potentials).

In addition to this previously unrecognized feature, our measurements in Xenopus oocytes also extend the study of Krapivinsky et al. (1998) on the most striking difference between Kir7.1 and all other channels of the Kir family, the shallow (nonsaturating) dependence of the Kir7.1 conductance on both voltage and $\left[\mathrm{K}^{+}\right]_{\mathrm{e}}$. In the range between 2 and $100 \mathrm{~mm}\left[\mathrm{~K}^{+}\right]_{\mathrm{e}}$ the measured Kir7.1 currents were almost independent of external $\left[\mathrm{K}^{+}\right]$. This 
A

Figure 9. Functional characteristics of mutant Kir7.1M125R channels in Xenopus oocytes. $A$, Kir7.1M125R currents in response to fast voltage ramps show a shift of reversal potentials with altering $\left[\mathrm{K}^{+}\right]_{\mathrm{e}}$, as indicated. $B$, Zero currents (reversal potentials, $\left.E_{\mathrm{Rev}}\right)$ of Kir7.1M125R currents, which are in close agreement with $E_{\mathrm{K}}$, are plotted versus the extracellular concentration of $\mathrm{K}^{+}\left(\left[\mathrm{K}^{+}\right]_{\mathrm{e}}\right)$ on a semi-logarithmic scale. The solid line is a linear regression fit to the data. $C$, Normalized chord conductances of Kir7.1M125R $\left(G / G_{\max }\right)$ in $96 \mathrm{mM}$ $\mathrm{K}^{+}$are plotted versus the membrane voltage (-). The $\bigcirc$ indicates the values for the wild-type Kir7.1. The $G-V$ relationship was fit by a single Boltzmann function $\left[G=1 / 1+\exp \left(V_{\mathrm{o}}-V_{1 / 2} / \mathrm{k}\right)\right]$, with a midpoint $V_{1 / 2}=-68.6 \mathrm{mV}$ and a slope factor $\mathrm{k}$ of $23 \mathrm{mV}$. D, Double-logarithmic plot of the Kir7.1M125R chord conductance ( as a function of $\left[\mathrm{K}^{+}\right]_{\mathrm{e}}$. The $\bigcirc$ indicates values for the wild-type Kir7.1). Conductances were measured at $G_{\max }$, and data were fit to $G=m\left(\left[\mathrm{~K}^{+}\right]_{\mathrm{e}}\right)^{n}$, where $m$ and $n$ are variables.

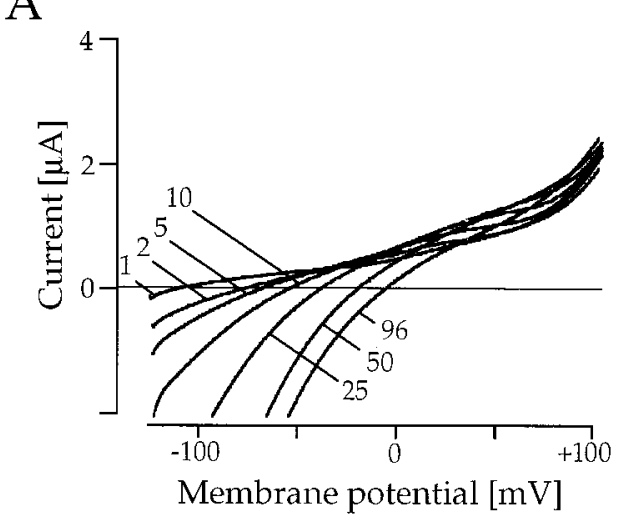

B

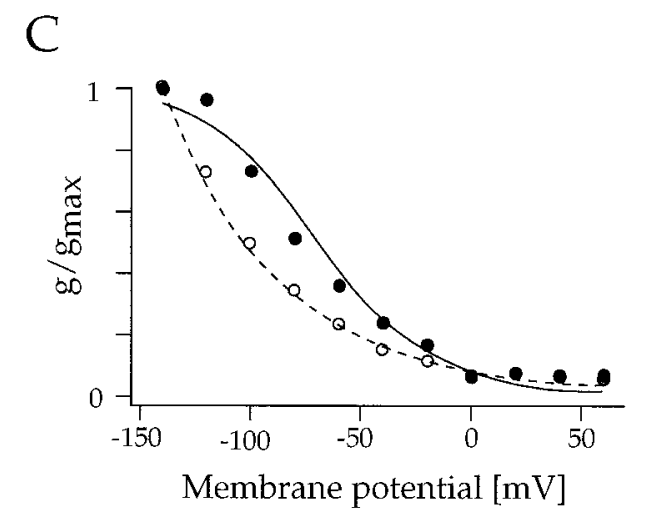

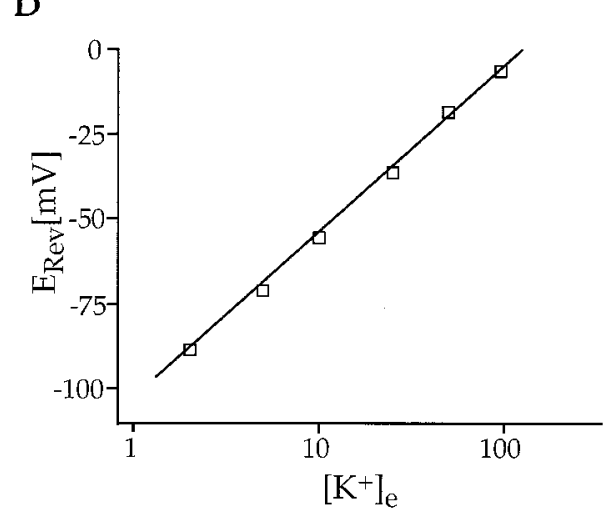

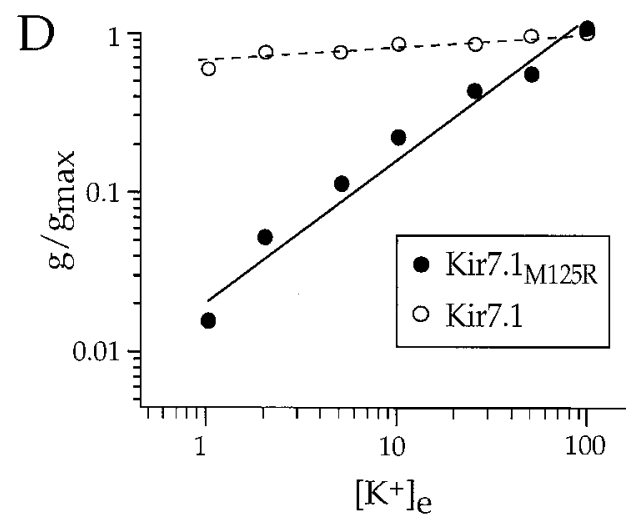

indicates that extracellular $\mathrm{K}^{+}$ions interact with the Kir7.1 channel (and with each other in the pore) in a different manner as compared with other inward rectifier channels. Strong electrostatic interactions between $\mathrm{K}^{+}$ions are to be expected as they move inside the pores, which is reflected in the dependence of $\mathrm{K}^{+}$ conductance on the concentration of external $\mathrm{K}^{+}$(and other ions). For instance, saturation of $\mathrm{K}^{+}$conductance as the $\left[\mathrm{K}^{+}\right]_{\mathrm{e}}$ is increased is an intrinsic feature of long Kir channel pores and can be described adequately by multi-ion barrier models (Lopatin and Nichols, 1996). Even in the absence of polyamine and $\mathrm{Mg}^{2+}$ block, the Kir channel conductance is approximately proportional to $\left[\mathrm{K}^{+}\right]_{\mathrm{e}}{ }^{0.5}$ in most Kir channels described so far (Sakmann and Trube, 1984; Lopatin and Nichols, 1996). The unconventional voltage and $\mathrm{K}^{+}$dependence of Kir7.1 channels may be attributable at least partially to the reduced charge density in the region adjacent to the $\mathrm{K}^{+}$selectivity filter, creating a higher energy barrier to stabilize the occupancy by $\mathrm{K}^{+}$.

Although from its charge it is unlikely to be the cationic binding site itself, the arginine may link the occupancy of $\mathrm{K}^{+}$ions at the outer part of the pore to the unblock of cytoplasmic $\mathrm{Mg}^{2+}$ and polyamines and thus the channel-gating mechanism (Kubo, 1996). For wild-type Kir7.1 lacking the arginine, a more moderate dependence of activation kinetics (possibly reflecting recovery from occlusion by internal blockers) on $\left[\mathrm{K}^{+}\right]_{\mathrm{e}}$ and a substantial outward current at low $\left[\mathrm{K}^{+}\right]_{\mathrm{e}}$ were observed. We showed that most of this outward component of Kir7.1 disappeared in the mutant Kir7.1M125R channels, which indeed may be indicative of an energetic coupling of the $\mathrm{Mg}^{2+}$ /polyamine binding with $\mathrm{K}^{+}$ occupancy at the outer pore region (Matsuda, 1991).
The crystal structure of the Streptomyces lividans KcsA channel that was solved recently to a resolution of $3.2 \AA$ now supplies a detailed view of what is thought to be the $\mathrm{K}^{+}$permeation pathway in potassium channels (Doyle et al., 1998). According to this view the $\mathrm{K}^{+}$channel signature G-Y-G (positions 121-123 in Kir7.1) representing the $\mathrm{K}^{+}$selectivity filter is directly adjacent to the residues addressed in this work. Lack of the arginine at position +2 in Kir7.1 channels changes the energy barrier for $\mathrm{K}^{+}$ions but likewise the electrostatic repulsion at the external entrance of the pore encountered by the blocking particles $\mathrm{Mg}^{2+}, \mathrm{Ca}^{2+}, \mathrm{Ba}^{2+}$, and $\mathrm{Cs}^{+}$. Intuitively, reduction of the positive charge density in a tetrameric channel should facilitate the access of $\mathrm{Ba}^{2+}$ and other nonpermeant cations to a deeper site in the channel. Thus the arginine at position +2 may be a rate-limiting barrier for $\mathrm{Ba}^{2+}$ open channel block, as was demonstrated in Kir2.1 subunits coexpressed with mutant subunits (Sabirov et al., 1997). Kir2.1 subunits devoid of the arginine148 showed an increased blocking rate, but no change in the steady-state block by $\mathrm{Ba}^{2+}$. Our results on Kir7.1 demonstrate that this view is not to be generalized but, instead, appears to vary considerably among different channel proteins. We observed only slightly reduced blocking rates (and thus virtually no occluded access) for $\mathrm{Ba}^{2+}$ to its binding site, but we report a $\sim 25$-fold increase in $\mathrm{Ba}^{2+}$ sensitivity of the mutant channels harboring the arginine. How can this apparently paradoxical finding be explained? The current view on why $\mathrm{K}^{+}$ions (Stokes radius, $1.33 \AA$ ), but not the smaller $\mathrm{Na}^{+}$ions $(0.95 \AA)$, penetrate the internal $\mathrm{K}^{+}$channel pore $(\sim 3 \AA$ in diameter $)$ is that an optimal conformation of the permeation pathway of the pore and of a close fit is required to form suitable bonding with $\mathrm{K}^{+}$and 
to lower the energy barriers (Armstrong, 1998; Doyle et al., 1998). From difference electron density maps it was hypothesized that the selectivity filter contains two simultaneously occupied binding sites between which a single $\mathrm{K}^{+}$ion may equilibrate rapidly (a third binding site is located in the aqueous inner cavity formed by the four pore helices). Dehydrated $\mathrm{Ba}^{2+}$ (Stokes radius, $1.35 \AA$ ) is similar in size to the permeant $\mathrm{K}^{+}$ions and, having two positive charges, may be balanced equally well between the two interaction sites of the inner pore with similar energy profiles. It therefore is conceivable that, by introducing the consensus arginine into the weakly sensitive $\operatorname{Kir} 7.1$ channel $\left(K_{\mathrm{i}}=670 \mu \mathrm{M}\right)$, the permeation pathway may acquire an overall structure more typical of Kir channels with relatively low energy barriers and high sensitivity for $\mathrm{Ba}^{2+}\left(K_{\mathrm{i}}=5-20 \mu \mathrm{M}\right)$. In other Kir channels the sensitivity to $\mathrm{Ba}^{2+}$ was found to be strongly dependent on other residues as well, e.g., in the M1-H5 linker region that contributes to the pore (Navaratnam et al., 1995; Töpert et al., 1998). In conclusion, the data reported here agree with the hypothesis that in epithelial Kir7.1 channels the replacement of the consensus arginine leads to a destabilization of (permeant and nonpermeant) cation occupancy in the pore and thus to unique permeation properties.

\section{REFERENCES}

Altschul SF, Madden TL, Shaffer AA, Zhang J, Miller W, Lipman DJ (1997) Gapped BLAST and PSI-BLAST: a new generation of protein database search programs. Nucleic Acids Res 25:3389-3402.

Armstrong C (1998) The vision of the pore. Science 280:56-57.

Baumann A, Krah-Jentgens I, Müller R, Müller-Holtkamp F, Seidel R, Kecskemethy N, Casal J, Ferrus A, Pongs O (1987) Molecular organization of the maternal effect region of the Shaker complex of Drosophila: characterization of an $I_{\mathrm{A}}$ channel transcript with homology to vertebrate $\mathrm{Na}^{+}$channel. EMBO J 6:3419-3429.

Cohen NA, Brenman JE, Snyder SH, Bredt DS (1996) Binding of the inward rectifier $\mathrm{K}^{+}$channel Kir2.3 to PSD-95 is regulated by protein kinase A phosphorylation. Neuron 17:759-767.

Doyle DA, Morais Cabral J, Pfuetzner RA, Kuo A, Gulbis JM, Cohen SL, Chait BT, Mackinnon R (1998) The structure of the potassium channel: molecular basis of $\mathrm{K}^{+}$conduction and selectivity. Science 280:69-77.

Fakler B, Brändle U, Glowatzki E, Weidemann S, Zenner HP, Ruppersberg JP (1995) Strong voltage-dependent inward rectification of inward rectifier $\mathrm{K}^{+}$channels is caused by intracellular spermine. Cell 80:149-154.

Fakler B, Schultz JH, Yang J, Schulte U, Brändle U, Zenner HP, Jan LY, Ruppersberg JP (1996) Identification of a titratable lysine residue that determines sensitivity of kidney potassium channels (ROMK) to intracellular pH. EMBO J 15:4093-4099.

Ficker E, Taglialatela M, Wible BA, Henley CM, Brown AM (1994) Spermine and spermidine as gating molecules for inward rectifier $\mathrm{K}^{+}$ channels. Science 266:1068-1072.

Fink M, Duprat F, Lesage F, Reyes R, Romey G, Heurteaux C, Lazdunski M (1996) Cloning, functional expression, and brain localization of a novel unconventional outward rectifier $\mathrm{K}^{+}$channel. EMBO J 15:6854-6862.

Goldstein SAN, Price LA, Rosenthal DN, Pausch MH (1996) ORK1, a potassium-selective leak channel with two pore domains cloned from Drosophila melanogaster by expression in Saccharomyces cerevisiae. Proc Natl Acad Sci USA 93:13256-13261.

Hagiwara S, Takahashi K (1974) The anomalous rectification and cation selectivity of the membrane of a starfish egg. J Membr Biol 18:61-80.

Hartmann HA, Kirsch GE, Drewe JA, Taglialatela M, Joho RH, Brown AM (1991) Exchange of conduction pathways between two related $\mathrm{K}^{+}$channels. Science 251:942-944.

Heginbotham L, MacKinnon R (1992) The aromatic binding site for tetraethylammonium ion on potassium channels. Neuron 8:483-491.

Hille B (1992) Ionic channels of excitable membranes. Sunderland, MA: Sinauer.

Hille B, Schwarz W (1978) Potassium channels as multi-ion single-file pores. J Gen Physiol 72:409-442.
Ho K, Nichols CG, Lederer WJ, Lytton J, Vassilev PM, Kanazirska MV, Hebert SC (1993) Cloning and expression of an inwardly rectifying ATP-regulated potassium channel. Nature 362:31-38.

Horio Y, Hibino H, Inanobe A, Yamada M, Ishii M, Tada Y, Satoh E, Hata Y, Takai Y, Kurachi Y (1997) Clustering and enhanced activity of an inwardly rectifying potassium channel, Kir4.1, by an anchoring protein, PSD-95/SAP90. J Biol Chem 272:12885-12888.

Horton RM, Hunt HD, Ho SN, Pullen JK, Pease LR (1989) Engineering hybrid genes without the use of restriction enzymes: gene splicing by overlap extension. Gene 77:61-68.

Kamb A, Iverson LE, Tanouye MA (1987) Molecular characterization of Shaker, a Drosophila gene that encodes a potassium channel. Cell 50:405-413.

Karschin C, Dissmann E, Stühmer W, Karschin A (1996) IRK(1-3) and GIRK(1-4) inwardly rectifying $\mathrm{K}^{+}$channel mRNAs are differentially expressed in the adult rat brain. J Neurosci 16:3559-3570.

Katz B (1949) Les constantes électriques de la membrane du muscle. Arch Sci Physiol 2:285-299.

Ketchum KA, Joiner WJ, Sellers AJ, Kaczmarek LK, Goldstein SAN (1995) A new family of outwardly rectifying potassium channel proteins with two pore domains in tandem. Nature 376:690-695.

Kotera T, Brown PD (1994) Evidence for two types of potassium current in rat choroid plexus epithelial cells. Pflügers Arch 427:317-324.

Krapivinsky G, Medina I, Eng L, Krapivinsky L, Yang Y, Clapham D (1998) A novel inward rectifier $\mathrm{K}^{+}$channel with unique pore properties. Neuron 20:995-1005.

Kubo Y (1996) Effects of extracellular cations and mutations in the pore region on the inward rectifier $\mathrm{K}^{+}$channel IRK1. Receptors Channels 4:73-83.

Kubo Y, Baldwin TJ, Jan YN, Jan LY (1993) Primary structure and functional expression of a mouse inward rectifier potassium channel. Nature 362:127-133.

Lesage F, Guillemare E, Fink M, Duprat F, Lazdunski M, Romey G, Barhanin J (1996) TWIK-1, a ubiquitous human weakly inward rectifying $\mathrm{K}^{+}$channel with a novel structure. EMBO J 15:1004-1011.

Lopatin AN, Nichols CG (1996) $\left[\mathrm{K}^{+}\right]$dependence of open channel conductance in cloned inward rectifier potassium channels (IRK1, Kir2.1). Biophys J 71:682-694.

Lopatin AN, Makhina EN, Nichols CG (1994) Potassium channel block by cytoplasmic polyamines as the mechanism of intrinsic rectification. Nature 372:366-369.

Lopez-Barneo J, Hoshi T, Heinemann SH, Aldrich RW (1993) Effects of external cations and mutations in the pore region on C-type inactivation of Shaker potassium channels. Receptors Channels 1:61-71.

Lu Z, MacKinnon R (1994) Electrostatic tuning of $\mathrm{Mg}^{2+}$ affinity in an inward-rectifier $\mathrm{K}^{+}$channel. Nature 371:243-246.

Ludewig U, Lorra C, Pongs O, Heinemann SH (1993) A site accessible to extracellular $\mathrm{TEA}^{+}$and $\mathrm{K}^{+}$influences intracellular $\mathrm{Mg}^{2+}$ block of cloned potassium channels. Eur Biophys J 22:237-247.

MacKinnon R, Yellen G (1990) Mutations affecting TEA blockade and ion permeation in voltage-activated $\mathrm{K}^{+}$channels. Science 250:276-279.

Matsuda H (1991) Effects of external and internal $\mathrm{K}^{+}$ions on $\mathrm{Mg}^{2+}$ block of inwardly rectifying potassium channels in guinea-pig heart cells. J Physiol (Lond) 435:83-99.

Methfessel C, Witzemann V, Takashi T, Mishina M, Numa S, Sakmann B (1986) Patch-clamp measurements on Xenopus oocytes: currents through endogenous channels and implanted acetylcholine receptor and sodium channels. Pflügers Arch 407:577-588.

Navaratnam DS, Escobar L, Covarrubias M, Oberholtzer JC (1995) Permeation properties and differential expression across the auditory receptor epithelium of an inward rectifier $\mathrm{K}^{+}$channel cloned from the chick inner ear. J Biol Chem 270:19238-19245.

Nichols CG, Lopatin AN (1997) Inward rectifier potassium channels. Annu Rev Physiol 59:171-191.

Nilsson C, Lindvall-Axelsson M, Owman C (1992) Neuroendocrine regulatory mechanisms in the choroid plexus-cerebrospinal fluid system. Brain Res Rev 17:109-138.

Noble D (1965) Electrical properties of cardiac muscle attributable to inward going (anomalous) rectification. J Cell Comp Physiol 66:127-136.

Papazian DM, Schwarz TL, Tempel BL, Jan YN, Jan LY (1987) Cloning of genomic and complementary DNA from Shaker, a putative potassium channel gene from Drosophila. Science 237:749-753.

Pardo LA, Heinemann SH, Terlau H, Ludewig U, Lorra C, Pongs O, 
Stühmer W (1992) Extracellular $\mathrm{K}^{+}$specifically modulates a rat brain $\mathrm{K}^{+}$channel. Proc Natl Acad Sci USA 89:2466-2470.

Paxinos G, Watson C (1986) The rat brain in stereotaxic coordinates. San Diego, CA: Academic.

Paxinos G, Ashwell KWS, Törk I (1994) Atlas of the developing rat nervous system. San Diego, CA: Academic.

Sabirov RZ, Tominaga T, Miwa A, Okada Y, Oiki S (1997) A conserved arginine residue in the pore region of an inward rectifier $\mathrm{K}$ channel (IRK1) as an external barrier for cationic blockers. J Gen Physiol 110:665-677.

Sakmann B, Trube G (1984) Conductance properties of single inwardly rectifying potassium channels in ventricular cells from guinea-pig heart. J Physiol (Lond) 347:641-657.

Schrempf H, Schmidt O, Kümmerlen R, Hinnah S, Müller D, Betzler M, Steinkamp T, Wagner R (1995) A prokaryotic potassium ion channel with two predicted transmembrane segments from Streptomyces lividans. EMBO J 14:5170-5178.

Schwalbe RA, Wang Z, Wible BA, Brown AM (1995) Potassium channel structure and function as reported by a single glycosylation sequon. J Biol Chem 70:15336-15340.

Stanfield PR, Davies NW, Shelton PA, Khan IA, Brammar WJ, Standen NB, Conley EC (1994) The intrinsic gating of inward rectifier $\mathrm{K}^{+}$ channels expressed from the murine IRK1 gene depends on voltage, $\mathrm{K}^{+}$, and $\mathrm{Mg}^{2+}$. J Physiol (Lond) 475:1-7.

Taglialatela M, Wible BA, Caporaso R, Brown AM (1994) Specification of pore properties by the carboxyl terminus of inwardly rectifying $\mathrm{K}^{+}$ channels. Science 264:844-847.

Taglialatela M, Ficker E, Wible BA, Brown AM (1995) C-terminus determinants for $\mathrm{Mg}^{2+}$ and polyamine block of the inward rectifier $\mathrm{K}^{+}$ channel IRK1. EMBO J 14:5532-5541.
Töpert C, Döring F, Wischmeyer E, Karschin C, Brockhaus J, Ballanyi K, Derst C, Karschin A (1998) Kir2.4: a novel K ${ }^{+}$inward rectifier channel associated with motoneurons of cranial nerve nuclei. J Neurosci 18:4096-4105.

Wang W, Hebert SC, Giebisch G (1997) Renal $\mathrm{K}^{+}$channels: structure and function. Annu Rev Physiol 59:413-436.

Wible BA, Taglialatela M, Ficker E, Brown AM (1994) Gating of inwardly rectifying $\mathrm{K}^{+}$channels localized to a single negatively charged residue. Nature 371:246-249.

Wischmeyer E, Karschin A (1996) Receptor stimulation causes slow inhibition of IRK1 inwardly rectifying $\mathrm{K}^{+}$channels by direct protein kinase A-mediated phosphorylation. Proc Natl Acad Sci USA 93:5819-5823.

Wischmeyer E, Lentes KU, Karschin A (1995) Physiological and molecular characterization of an IRK-type inward rectifier $\mathrm{K}^{+}$channel from a tumour mast cell line. Pflügers Arch 429:809-819.

Yang J, Jan YN, Jan LY (1995) Control of rectification and permeation by residues in two distinct domains in an inward rectifier $\mathrm{K}^{+}$channel. Neuron 14:1047-1054.

Yang J, Yu M, Jan YN, Jan LY (1997) Stabilization of ion selectivity filter by pore loop ion pairs in an inwardly rectifying potassium channel. Proc Natl Acad Sci USA 94:1568-1572.

Yellen G, Jurman M, Abramson T, Mackinnon R (1991) Mutations affecting internal TEA blockade identify the probable pore-forming region of a $\mathrm{K}^{+}$channel. Science 251:939-942.

Yool AJ, Schwarz TL (1991) Alteration of ionic selectivity of a $\mathrm{K}^{+}$ channel by mutation of the H5 region. Nature 349:700-704.

Zhou XL, Vaillant B, Loukin SH, Kung C, Saimi Y (1995) YKC1 encodes the depolarization-activated $\mathrm{K}^{+}$channel in the plasma membrane of yeast. FEBS Lett 373:170-176. 